\title{
EL G20 Y LOS PAÍSES EMERGENTES
}

GÜNTHER MaiHold

ZirahuÉn Villamar

EL ORDEN INTERNACIONAL ACTUAL se ha caracterizado por ser un "mundo de diversidad y complejidad, una arquitectura descentrada en cuanto al manejo del orden, con presencia de viejos y nuevos poderes, con un papel mayor para la gobernanza regional". ${ }^{1}$ En este contexto de mayor variedad, más oportunidades y extendido autocontrol sobre las opciones que cada actor desea desarrollar, los retos de la política exterior también sufren cambios: para cada país, independientemente de su tamaño, existen opciones en su inserción internacional, lo que implica la necesidad de definir o renovar desde su respectiva estrategia nacional una apreciación correcta o un replanteamiento de lo que necesita y puede obtener de su entorno.

En el marco internacional, la creciente presencia de algunos países del Sur se ha subsumido en el siglo xxi bajo el rubro de países emergentes, una construcción cuyo padrino fueron las agencias internacionales de calificación de riesgos como Goldman Sachs, interesados en promover sus productos financieros correspondientes a nuevos mercados. Estos mercados emergentes se han convertido en el foco de interés, a los que corresponden novísimos acrónimos lanzados al debate para aumentar su atractivo frente a posibles inversionistas. Así han

${ }^{1}$ Acharya, Amitav, The End of American World Order, Cambridge, TJ International Ltd, 2014, p. 8. 
surgido diversas agrupaciones como BRICs, ${ }^{2}$ MIST, ${ }^{3}$ Next Eleven, ${ }^{4}$ etc., que han dado paso hacia un bricolage global. $^{5}$

Muchos países emergentes parecen haber tomado la decisión de ingresar y mostrar su presencia en el mayor número de espacios de política internacional. Es un fenómeno que suele denominarse "pertenencias múltiples", el cual conlleva importantes consecuencias políticas porque cada pertenencia implica un sistema más o menos marcado de lealtades. Este hecho que pone de relieve el problema de la compatibilidad de dichas lealtades con aquella reclamada por la síntesis política global de cada grupo, es decir, un profundo problema de identidad para su política exterior. Uno de los nuevos escenarios de esta negociación de presencias es el Grupo de los 20 (G20), donde una agrupación selecta de países del Sur ha encontrado la posibilidad de desplegar sus capacidades para impactar sobre las decisiones internacionales. La lógica que acompaña este esfuerzo del G20 como systemic hub ante la crisis económica de 2008-2009 en Estados Unidos y Europa es la idea de construir like-mindedness, es decir, formar una arena en la que pueda ser organizada la confluencia de voluntades de las más importantes economías a nivel mundial, con el fin de contrarrestar ciertas dinámicas en los mercados internacionales las cuales rebasan claramente las capacidades de cada país a nivel mundial. En tanto, like-mindedness no es el punto de partida, sino el punto de arribo del G20, por lo que en el presente texto se tratarán de reseñar las dinámicas en este camino a una mayor convergencia de los países emergentes en el ruedo de multilateralismo selectivo e informal.

El texto revisará el papel que han jugado los países emergentes en el marco del G20, considerado el foro central en el que los países desarrollados han abierto un espacio simbólico de concertación con ellos a lo largo de la última década. Las interrogantes formula-

${ }^{2}$ Brasil, Rusia, la India y China (posteriormente Sudáfrica).

${ }^{3}$ México, Indonesia, Corea del Sur y Turquía.

${ }^{4}$ Bangladesh, Corea del Sur, Egipto, Filipinas, Indonesia, Irán, México, Nigeria, Pakistán, Turquía y Vietnam.

${ }^{5}$ James H. Mittelman, "Global Bricolage: Emerging Market Powers and Polycentric Governance”, Third World Quarterly, vol. 34, núm. 1, 2013, pp. 23-37. 
das aquí son, en primer lugar, si los países emergentes han podido desarrollar una representación de sus intereses en este ámbito informal; y, en segundo lugar, si han desarrollado una identidad propia, un patrón propio de actividad diplomática, ${ }^{6}$ al superar las dudas sobre su compromiso y responsabilidad ${ }^{7}$ así como sus capacidades políticas. $^{8}$

Estos cuestionamientos salen a flote a raíz del hecho de que los diferentes grupos apunta(ba)n hacia las capacidades de ciertos mercados con gran potencial de futuro y podrían convertirse en locomotoras del crecimiento económico a nivel mundial. Y, porque el interés que se ha prestado a los "emergentes" con el lema "The West and the Rest" ${ }^{9}$ ha llamado por fin la atención del orden occidental, aunque, ante la reducción de las expectativas de crecimiento en años recientes, es considerado ya por algunos como el "Hype of the rest". ${ }^{10}$ Estos discursos de "emergencia" tienen en la mira los cambios que podrían tocar a la puerta del multilateralismo a raíz de la multiplicación de actores, sus intereses de reconocimiento y participación con narrativas diferentes a los esquemas establecidos. Adicionalmente, a consecuencia de que los países emergentes ya no se limitan a los esquemas multilaterales clásicos como el Grupo de los 77 (G77) y todo el marco de la Organización de las Naciones Unidas (ONU), ha cambiado profundamente el panorama mundial. Son el empeño y la insistencia, sumados a la necesidad de los países tradicionales del G7 de buscar bases más amplias para lograr la recuperación económica ante sus crisis

${ }^{6}$ Jorge Heine, "Will They Have Table Manners? The G20, Emerging Powers and Global Responsibility", South African Journal of International Affairs, vol. 17, núm. 1, 2010, pp. 1-11.

${ }^{7}$ Patrick Stewart, "Irresponsible Stakeholders?: The Difficulty of Integrating Rising Powers", Foreign Affairs, vol. 89, núm. 6, 2010, pp. 44-53.

${ }^{8}$ Jorge G. Castañeda, "Not Ready for Prime Time. Why Including Emerging Powers at the Helm Would Hurt Global Governance", Foreign Affairs, vol. 89, núm. 5, 2010, pp. 109-115.

${ }^{9}$ Ver el clásico Niall Ferguson, Civilization: The West and the Rest, Nueva York, Penguin Books, 2011.

${ }^{10}$ Dani Rodrik, "Back to Fundamentals in Emerging Markets", Project Syndicate, 13 de agosto de 2015, http:/ / www.project-syndicate.org/commentary/emerging-market-growth-by-dani-rodrik-2015-08, consultado el 13 de agosto de 2015. 
internas, los que han abierto a los llamados "emergentes" una nueva oportunidad de participar a nivel internacional.

Para evaluar la actuación de los países emergentes en el G20 -y sus implicaciones-, este texto asume que, ante la heterogeneidad de actores tan disímbolos como Arabia Saudita, Argentina, Brasil, China, Corea del Sur, la India, Indonesia, México, República de Sudáfrica y Turquía, aquí solo será posible destacar algunos rasgos generales de la representación de la diversidad de identidades de los países, así como de sus variados intereses, todo lo cual se resume en la pregunta por la funcionalidad del Grupo como foro para hacerse escuchar. Dicha limitante obedece a que el énfasis del examen presente es el G20 y su potencial para la coordinación de políticas comunes de los emergentes. De esta forma, el análisis permite inscribirse en un debate actual que orienta la discusión por un lado al hecho de que los países emergentes han utilizado al G20 desde una postura reformista (norm-making); o, por el otro lado, al hecho de que los emergentes han sido cooptados en el marco de los acuerdos emanados desde este foro (norm-taking). Así, nuestra tesis central se apoya en la afirmación de que el espacio del G20 funciona efectivamente como una instancia de socialización de los países emergentes en el orden existente desde la intervención de estos actores en esta nueva arena multilateral. ${ }^{11}$

El tratamiento de este caso sigue metodológicamente el modelo de la "gobernanza global a través de "clubes""12 que enfatiza las características de flexibilidad, informalidad y la vinculación laxa en cuanto a valores e instrumentos. El texto está constituido por una sección que problematiza la emergencia de algunos países del Sur y las tensiones internas a esta categoría. En la siguiente sección se expone el G20 como un foro en permanente evolución temática y lo destaca en su importancia. La sección siguiente subraya la funcionalidad del G20 desde la perspectiva de los países emergen-

${ }^{11}$ Kai Alderson, "Making Sense of State Socialization", Review of International Studies, vol. 27, núm. 3, 2001, pp. 415-433.

12 Bernhard Rinke y Ulrich Schneckener, "Informalisation of World Politics? Global Governance by Clubs", en Development and Peace Foundation / Institute for Development and Peace (orgs.), Global Trends 2013. Peace Development-Environment, Fráncfort, Fischer, 2012, pp. 21-35. 
tes en articulación con los países desarrollados, tanto del formato en sí, como a partir de cinco temas específicos a guisa de ejemplos (a saber: la reforma de organismos financieros internacionales, acceso a información y conocimientos, definición de normas, establecimiento de marcos de operación comunes y seguridad alimentaria), con la finalidad de ilustrar el valor del Grupo como instancia de socialización. La sección que prosigue está dedicada a analizar la coordinación de políticas de los países emergentes en foros externos al G20, lo que refuerza la impresión de la variopinta identidad de los miembros del Grupo y sus vínculos con el Sur Global. Por último, se subraya la centralidad del Grupo y el debate en el que se ubica su significado respecto a las posibilidades mencionadas anteriormente, ya sea como foro de transformación mundial con los países emergentes, o ya de su cooptación.

\section{Los países emergentes y el Sur (Global South). El tema DE LAS IDENTIDADES}

El Sur como explicación de la creciente unidad de los países en vías de desarrollo ha surgido como referente obligatorio de todos los debates sobre el futuro de las relaciones Norte/Sur por la creciente expansión de la cooperación al desarrollo y la definición de posiciones conjuntas entre sus integrantes. Mientras que en el pasado las referencias en cuanto a la agencia fueron el G77 y el Movimiento de los Países No-Alineados (MPNA), hoy en día, a pesar de un peso económico creciente, sigue presente esta categoría política con un alto nivel de heterogeneidad, situación que limita su uso en términos analíticos, aunque abra un nuevo acceso conceptual. ${ }^{13}$ Sin embargo, desde el punto de vista de las relaciones internacionales se plantean las preguntas de si el ascenso de algunos países, denominados "emergentes" desde el Sur Global, puede ser considerado efectivamente un aumento en el peso y el poder del conjunto de países emergentes en una medida global, y de cómo

13 Caroline Levander y Walter Mignolo, "The Global South and World Dis/ Order", The Global South, vol. 5, núm. 1, 2011, pp. 1-11. 
tales incorporan sus correspondientes intereses en los patrones de la gobernanza global. ${ }^{14}$ En caso de que el G20 funcione como el ruedo en el que se negociará el power shift entre Norte y Sur -una de las inquietudes que anima los debates-, es menester reflexionar sobre la lealtad de los países emergentes con el Sur Global, o su posible cooptación con los grandes poderes y la subsecuente transformación de su identidad y su comportamiento con base en el reconocimiento de su estatus distintivo frente a los demás países en vías de desarrollo, lo que asimismo podría implicar un daño a la creciente importancia de la relación Sur-Sur. ${ }^{15}$

Una primera revisión de las orientaciones en materia de política exterior promovidos por los países emergentes arroja un diagnóstico de políticas exteriores complejas, contradictorias y a veces inconsistentes, ${ }^{16}$ resultado del actuar en diferentes escenarios acorde a sus múltiples pertenencias. La posible incoherencia radicaría básicamente en las identidades ${ }^{17}$ de esos países, que justo experimentan un complejo proceso dispar e inacabado de formación de dichas identidades. Así, se han reconocido algunas características que permiten esclarecer su posicionamiento en el marco

${ }^{14}$ Augusto de la Torre, Tatiana Didie, Alain Ize, Daniel Lederman y Sergio L. Schmukler, América Latina y el ascenso del Sur: Nuevas prioridades en un mundo cambiante, Washington, D. C., Banco Mundial, 2015.

${ }^{15}$ Según la Asamblea General de las Naciones Unidas (AGNU), en la Resolución 64/222, titulada "Nairobi Outcome Document of the High-level United Nations Conference on South-South Cooperation” del 21 de diciembre de 2009, se puede definir a la cooperación Sur-Sur como "una empresa común de los pueblos y los países del Sur, surgida de experiencias compartidas y afinidades, sobre la base de unos objetivos y una solidaridad comunes, y guiada, entre otras cosas, por los principios del respeto de la soberanía y la implicación nacionales, libres de cualquier condicionalidad". http://www.un.org/en/ga/search/view_doc.asp?symbol =A/RES $/ 64 / 222$, consultado el 15 de marzo de 2015.

${ }^{16}$ Andrew F. Cooper y Daniel Flemes, "Foreign Policy Strategies of Emerging Powers in a Multipolar World: An Introductory Review", Third World Quarterly, vol. 36, núm. 6, 2013, p. 945.

${ }^{17}$ En el sentido de Alexander Wendt como ciertas ideas respecto de uno dadas una condición, en función de lo que se es y lo que se espera ser por los demás. Alexander Wendt, Social Theory of International Politics, Cambridge, Cambridge University Press, 1999, p. 170. 
del G20 y otros procesos internacionales; ${ }^{18}$ parece que su comportamiento sigue un molde explícitamente intergubernamental, que relega a un segundo plano la participación de otros actores privados y no gubernamentales, de manera que responde a sus motivos de restringir la participación a representantes gubernamentales y funcionarios de organismos internacionales en los debates. Los ejes centrales de la articulación de sus intereses están ligados a las prioridades del desarrollo nacional, por lo que prefieren una participación selectiva en los asuntos multilaterales para tratar de reducir posibles costos que puedan surgir como resultado de un involucramiento demasiado profundo, y garantizar al mismo tiempo la ampliación de su estatus en aquellos temas que sean de su interés primordial.

Una señal de esta presencia en muchos espacios de concertación y coordinación es la percepción de ser al mismo tiempo países en vías de desarrollo y potencias emergentes y asimismo receptor y donante de cooperación al desarrollo. De allí se delinean los roles que se han adjudicado a los países emergentes con su creciente peso. Por ejemplo, en el marco del G20 tratan de satisfacer tanto la agenda nacional como las tareas derivadas de la pertenencia al Sur Global: dependiendo de las respectivas tradiciones en su política exterior se han podido identificar tres papeles que se proponen llevar a cabo en el marco del G20 y que se refieren a la función del agenda setting, el papel del broker así como de un enfoque que busca formar coaliciones. ${ }^{19}$ Llama la atención que los dispares acercamientos ${ }^{20}$ ofrecen la posibilidad de realzar al propio país entre los demás integrantes del G20 y mantener al mismo tiempo un anclaje en sus referentes del Sur Global u otras identidades como los BRICS o IBSA. ${ }^{21} \mathrm{El}$ potencial de esta posibilidad de operar en múltiples ámbitos y con contrapartes

18 Véase Andrew Cooper y Daniel Flemes, op. cit., p. 947.

${ }^{19}$ Como señalan Cooper y Flemes, y según será analizado con mayor detalle en páginas siguientes. Ibid., p. 949.

${ }^{20}$ Randall Schweller diferencia funciones de "spoiler, supporter y shirker" como modelos de roles para los países emergentes, en "Emerging Powers in an Age of Disorder”, Global Governance, vol. 17, núm. 3, 2011, pp. 285-297.

${ }^{21}$ La India, Brasil y Sudáfrica. 
variables parece ser la fórmula para mantener los compromisos en las diferentes arenas internacionales, lograr el cumplimiento de los objetivos nacionales en diferentes escenarios y controlar los riesgos de una posición de liderazgo aprovechando los altos niveles de visibilidad, resultado de la membrecía en el G20.

Con el G20 comienza una transformación de los países emergentes devenidos en miembros de la agrupación en países "sistémicamente importantes" para el desarrollo de la economía mundial. En términos de identidad, el ingreso al G20 podría considerarse una escena de la formación de la identidad de esos países a partir del aprendizaje que experimentan a través de un proceso de "socialización", que consiste en satisfacer las expectativas que tienen los países desarrollados de la conducta de los emergentes en dicha calidad. ${ }^{22}$ La socialización en el G20 como atracción para acomodar las inquietudes de algunos países del Sur Global relegó a los demás a un segundo plano, lo que pone de relieve los problemas de legitimidad y representatividad de esta selección. Un vistazo a las potencias emergentes miembros del G20 arroja un resultado similar. En América Latina, por ejemplo, Brasil se convirtió en uno de los protagonistas del G20 a nivel de los países emergentes con su aspiración de ser un "poder principal" de la política internacional. México puso de relieve su perfil de "país puente" con base en su emergencia "autodeclarada", mientras que Argentina parece, por lo menos, un "emergente atípico", ya que no ha tenido la dinámica económica que caracteriza a los otros dos integrantes latinoamericanos del G20.

Así se explica la propensión a una conducta de reserva en el marco del G20 (aún en este espacio informal, que se examina a continuación) por las posibles obligaciones y costos que podrían implicar ciertas posiciones asumidas en este foro. ${ }^{23}$ Asimismo, especialmente los países grandes -como Brasil- optan por preferir una posición de hedging: ${ }^{24}$ limitar a su vez una solución de pro-

${ }^{22}$ Alexander Wendt, op. cit., pp. 170 y 324.

${ }^{23}$ Andrew F. Cooper, "Las potencias emergentes y el nuevo multilateralismo", Revista Mexicana de Política Exterior, núm. 94, 2012, p. 162.

${ }^{24}$ Hedging puede ser definido como "to cultivate a middle position that forestalls or avoids having to choose one side [or one straightforward policy stance] at 
blemas colectivos de un grupo porque no se desea dañar su presencia en otros espacios, ${ }^{25}$ como, con el mismo ejemplo brasileño, en el marco sudamericano de la Unasur, el Mercosur o de su membrecía en el grupo BRICs.

\section{El G20 COMO ESPACiO DE LA PROYECCióN DE LOS PAÍSES EMERGENTES}

Si se considera el G20 como "la culminación de un proceso de ampliación del núcleo de la gobernanza mundial para incluir a las potencias en ascenso o emergentes al lado de las potencias consolidadas o tradicionales y dar a todas el mismo grado de participación e influencia”, ${ }^{26}$ parece oportuno revisar si este proceso de ascenso ha tenido avances sustanciales desde su inicio con la primera cumbre del G20 a nivel de sus líderes en noviembre de 2008 en Washington, D. C. Cada cumbre o reunión ministerial del G2027 abre la oportunidad para una articulación nueva de los intereses de los países emergentes, ya sea en cuanto a sus posiciones, o sea con respecto a las alianzas que se están tejiendo dentro de este foro; así, en el caso de la reciente reunión de los ministros de finanzas y los gobernadores de los Bancos Centrales del Grupo en Washington, D. C. (en paralelo a las Reuniones de Primavera del Banco Mundial y el Fondo Monetario Internacional) en abril de 2015, la crítica por parte de los representantes de los países emergentes se enfocaba en el hecho de que el Congreso estadounidense no había ratificado las modificaciones a la participaciones de los miembros en el Fondo Monetario Internacional (FMI; véase el apartado 4.1 de este texto). Este reclamo parece ser una reminiscencia de los inicios de los debates sobre un posible papel protagónico de los países

the obvious expense of another", $c f r$. Vincent Charles Keating y Jan Ruzicka, "Trusting Relationships in International Politics: No Need to Hedge", Review of International Studies, vol. 40, núm. 4, 2014, p. 761.

${ }^{25}$ Andrew Cooper, op. cit., p. 157.

${ }^{26}$ John Kirton, "El G20, el G8, el G5 y el papel de las potencias en ascenso", Revista Mexicana de Política Exterior, núm. 94, 2012, pp. 164.

${ }^{27}$ Los ministros de Finanzas se siguen reuniendo desde 1999 en este formato. 
emergentes en la gobernanza económica global que se había restringido a un círculo limitado de siete países. En un inicio la misma conformación del G20 había sido interpretada como un avance significativo, tal y como lo demuestra la siguiente reseña histórica del desarrollo político del G7 al G20, en el cual enfatizamos, en términos de identidad, en la transformación del criterio like-minded como punto de partida (en el caso del G7) o como punto de llegada (con referencia al G20).

\subsection{El modelo de "gobernanza de clubes" y el papel de las potencias emergentes}

El G7 fue creado en 1975 y marca el inicio de un foro informal de gobernanza global, organizado por fuera del sistema multilateral de Naciones Unidas. Se privilegiaba este formato para discutir en un grupo reducido los grandes temas de la economía mundial, que en ese momento se encontraba en medio de una era global de desestabilización económica. El Grupo de las economías de mercado más grandes, que originalmente incluía sólo Alemania, Estados Unidos, Francia, Japón, Italia y Reino Unido, un año más tarde agregó a Canadá. Las otras economías, que no pertenecían al autodenominado G7, lo vieron como la reacción de un núcleo duro de economías capitalistas que anhelaban imponer su modelo de desarrollo por medio de la selección de los caminos para salir de la crisis. El discurso seguía la lógica de una confrontación de perspectivas entre el Norte y el Sur, representado este último en las identidades del Tercer Mundo y del Movimiento de Países No Alineados (MPNA), sus aspiraciones y narrativas, motivadas por la creación de un Nuevo Orden Económico Internacional (NOEI). El G7 fue visto como un foro que más bien vivía con base en la exclusión, siguiendo la lógica de poder prescindir del resto del mundo para la solución de los problemas.

En su evolución, el G7 fortaleció su papel como el principal foro de discusión en materia económica internacional y de esbozo de coordinación de políticas nacionales de los países que lo conformaban, a partir de los elementos característicos que se describen 
más adelante. La desaparición de la Unión de Repúblicas Socialistas Soviéticas y la disolución del orden mundial bipolar permitió que en 1994 la Federación Rusa se integrara al Grupo, que se denominó en lo sucesivo G8. En la actualidad se ha vuelto a la formación original de siete miembros, como pudo comprobarse en el primer semestre del año 2014, en que, luego de los conflictos entre Rusia y Ucrania y la intervención militar rusa en Crimea, los países del G7 boicotearon la reunión del G8 organizada por Rusia. El G7 partió de una característica like-minded, es decir, de una identidad común de ser democracias y las economías de mercado de mayor peso mundial, la que a su vez legitimaba, desde su propia autovaloración, una hegemonía de grupo de los responsables a nivel global.

Las ventajas del G7 para sus miembros han consistido en permitirles una mayor visibilidad a nivel mundial, como el grupo central de la economía mundial en términos de una gobernanza organizada dentro del núcleo transatlántico. ${ }^{28}$ Las capacidades de proyección después en el G8 fueron vistas desde el inicio como un eje central para ganar credibilidad y aceptación global, allende los países miembros. Así se optó por ampliar el círculo de los integrantes por medio de un proceso denominado outreach con la invitación formal a los llamados "O5" a entablar conversaciones: África del Sur, la India, China, Brasil y México. Esta fórmula, que después asumió el nombre de "Proceso de Heiligendamm", correspondiente a la Cumbre del G20 celebrada en Alemania en $2007,{ }^{29}$ por un lado reveló la búsqueda de mayor representatividad y efectividad por medio de un proceso formal de ampliación por parte del G7, y por el otro puso de relieve el interés de los "nuevos invitados a la mesa" por mantener su doble identidad de países en desarrollo fieles a su solidaridad con el Sur Global y sus ambiciones de poderes emergentes pujantes. ${ }^{30}$ De los dos lados se

28 Günther Maihold, "Del G8 al G20 y más allá: efectividad y legitimidad", Cuadernos de la Cátedra Humboldt: El G20 y El Nuevo Orden Internacional, núm. 1, 2012, pp. 25-50.

${ }^{29}$ Katharina Gnath, A Group's Architecture in Flux: The G8 and the Heiligendamm Process, Bolonia, European University Institute, 2010.

${ }^{30}$ Andrew F. Cooper, "The Heiligendamm Process. Structural Reordering and Diplomatic Agency”, en Andrew F. Cooper y Agata Antkiewicz (comps.), Emerging 
hizo evidente una "mentalidad de clubes" ${ }^{11}$ que rechaza la regulación de la asistencia ejercida por otros y trata al mismo tiempo de mantener la exclusividad de los asistentes. Sin embargo, el modelo de invitar a los G5 por una reunión corta a la "mesita" sin inclusión de pleno derecho molestaba a sus representantes en varias reuniones del G8, que reclamanban una membrecía plena. Este anhelo hizo surgir también las aspiraciones de otras naciones emergentes, elevando así el modelo de "gobernanza a través de clubes" a los límites de su posible funcionamiento.

Recurrir al formato de "clubes" para lograr gobernanza en ciertas áreas, no solamente para sus mismos integrantes, sino también provechoso para otros Estados, sería una alternativa. Así, se espera que este formato de gobernanza a través de "clubes" sea capaz de proporcionar los siguientes elementos: ${ }^{32}$

- Disponer de información y conocimientos

- Poder movilizar recursos

- Definir normas y estándares

- Realizar medidas concretas

- Acordar marcos de acción comunes

Visto así, la gobernanza a través de clubes asume una posición intermedia entre el multilateralismo formalizado e institucionalizado y el multilateralismo selectivo, tal y como se expresa por medio de coaliciones ad hoc o redes informales de carácter transnacional de funcionarios y/o de cabildeo. Para poder producir resultados, es central que en los formatos de gobernanza por medio de clubes se observe menos la coincidencia de posiciones en cuanto a contenidos de entrada, y que más bien sea posible organizar, alrededor del problema específico por resolver, los actores relevantes en cuanto a su capacidad de movilizar recursos económicos, sociales y de legiti-

Powers in Global Governance: Lessons from the Heiligendamm Process, Waterloo, CIGI, 2008, pp. 1-18.

31 Timothy M. Shaw, Agata Antkiewicz y Andrew F. Cooper, "The Logic of the в (R) ICSAM Model for Global Governance", en Andrew F. Cooper y Agata Antkiewicz (comps.), op. cit., p. 38.

${ }^{32}$ Ulrich Schneckener, "The Opportunities and Limits of Global Governance by Clubs", German Institute for International and Security Affairs, 2009 (SWPComments C 22). 
midad para producir bienes colectivos. ${ }^{33}$ En la práctica política se ha demostrado que en un mundo multilateral fragmentado se han configurado, en el formato de "clubes", agrupaciones muy diferentes entre sí, motivadas por una comunidad de valores, por el interés de una (re)distribución del poder o de la riqueza ${ }^{34}$ con un concomitante aumento en la complejidad de las negociaciones y una tentación creciente de parte de algunos gobiernos de optar por una lógica del forum-shopping en el afán de tratar de maximizar las opciones para la implementación de sus intereses nacionales. ${ }^{35}$

Por lo tanto, el G20 aspira a cumplir mucho más que el G7, con la necesidad de poder fungir como foro para generar convergencias ante las múltiples pertenencias de sus miembros, lo cual implica una limitante en la búsqueda de consensos. Aparte, no existe homogeneidad con respecto a los criterios que animaron en su inicio al G7 en cuanto a su meta de fomentar la democracia y los derechos humanos a nivel global, ya que algunos países integrantes no logran cumplir con estos criterios en su desarrollo.

Gradualmente, a lo largo de dos décadas de existencia del G7, éste desempeñó un papel central y exclusivo en la gobernanza económica global, en contraste con una deseable estructura más representativa que contara con la participación de otras economías (el "Sur"), como fue descrito por la Comisión sobre Gobernanza Global en 1994. ${ }^{36}$ Aunque la exclusividad del Grupo no desapareció, las realidades económicas globales, marcadas esencialmente por la adversidad, del último lustro del siglo xx y la primera década del xxi pusieron sobre la mesa el tema de la pertinencia de la inclusión de otros países en sus discusiones: los

${ }^{33}$ Ibid., p. 4 ss.

34 Thomas Manz, “Allianzen und Gruppen im Global Governance System - Multilateralismus zwischen partikularen Interessen und universellen Anforderungen”, Internationale Politik und Gesellschaft, núm. 2, 2007, p. 41.

35 Marc L. Busch, "Overlapping Institutions, Forum Shopping, and Dispute Settlement in International Trade”, International Organization, vol. 61, núm. 4, 2007, pp. 735-761.

${ }^{36}$ Commission on Global Governance, Our Global Neighborhood. The Report of the Commission on Global Governance, Report, Oxford University Press, 1995. 
países emergentes, lo que dio lugar a una nueva formación que se describirá a continuación.

\subsection{El G20 de 1998-2008: de crisis en crisis}

La crisis económica y financiera internacional entre 1997 y 1998 azotó de forma severa a los países del sureste de Asia y, por medio de los tradicionales canales de contagio, también afectaron los mercados financieros de otros países -emergentes y establecidos-; una iniciativa alemana (que en 1999 presidía la dirigencia rotatoria del G8) trajo como consecuencia un diálogo especializado, a nivel de Ministros de Finanzas y banqueros centrales, en el que participaron las economías sistémicamente significativas en materia de políticas económicas y financieras clave, dando lugar a la creación, en ese mismo 1999, del G20. Los participantes de este nuevo club fueron, además de los integrantes del G8, Arabia Saudita, Argentina, Australia, Brasil, China, Corea del Sur, la India, Indonesia, México, Sudáfrica y Turquía, así como la Unión Europea. El perfil ministerial económico y financiero, la presencia de los bancos centrales, y la inclusión del Director Gerente del Fondo Monetario Internacional y del Presidente del Banco Mundial (BM), así como la participación plena de las economías emergentes, en ese momento dotaron al grupo con una calidad inusual en los clubes de gobernanza: una mayor representatividad de los intereses del Sur en foros donde el Norte había tenido no solamente la prioridad, sino también el monopolio de interpretación de los hechos. Sin embargo, no debe soslayarse que la propuesta fue una ampliación y especialización de un círculo existente, no la creación de uno nuevo. No obstante, el G20 puede leerse como el reconocimiento a los cambios que en la economía mundial empezaban a notarse en términos del aumento del peso específico en aspectos financieros, comerciales y productivos internacionales de aquellos países del Sur que iniciaron el tránsito hacia economías más dinámicas y poco a poco más desarrolladas (véase la tabla 1). Se trataba, en síntesis, del "foro diseñado para promover el diálogo en asuntos de gobernanza económica y financiera global en el que naciones tanto del Norte y 
del Sur se reúnen para discutir e intentar administrar problemas sistémicos comunes". ${ }^{37}$ Ya no dominaba un punto de partida en común, más bien el mismo proceso iba encauzando los debates y generaba puntos de vistas conjuntos que permitiesen acciones concretas. Like-mindedness era y sigue siendo un objetivo a lograr, resultado de un proceso de discusión y negociación, que parte de posiciones diversas y muchas veces encontradas. Los trabajos del G20 se concibieron bajo la dirigencia de una presidencia anual rotatoria, que se coordinaría a sí misma con las presidencias saliente y próxima entrante en el esquema Troika. Pero al igual que en G7, al no haber una carta, estatuto o reglamento, da libertad a sus miembros para elegir las formas en que se construye su agenda, se toman las decisiones o las formas en que se implementan y supervisan. Un acuerdo inicial consistió en turnar dicha dirigencia entre países desarrollados y emergentes. ${ }^{38}$

En poco menos de diez años desde la crisis del sudeste asiático, que incluyen el experimento del $\mathrm{O} 5$ y G7/8 y su "compromiso constructivo" entre economías desarrolladas y emergentes de mediados de la primera década del siglo xxI, al igual que la severa crisis económica, cuyos primeros indicios aparecieron en 2007, que culminó en 2008 y que terminó el desplome internacional en 2009, el G20 mutó y se convirtió en un espacio aún más heterogéneo, por cuanto agenda y responsabilidad, con lo que incrementó el protagonismo de los países emergentes como factor de una diversidad de aspiraciones desconocido hasta estos momentos en el G7.

\subsection{El G20: la búsqueda del consenso en la crisis y la postcrisis}

Con la declaración de quiebra de la firma Lehman Brothers de septiembre de 2008 se evidenció el empeoramiento de la crisis financiera y se vieron claramente las limitantes del modelo de gestión

${ }^{37}$ Mark Beeson y Stephen Bell, "The G20 and International Economic Governance: Hegemony, Collectivism, or Both?”, Global Governance, vol. 15, núm. 1, 2009, pp. 67-86.

38 G20, The Group of 20: A History, G20 Information Centre, 2008 en http:// www.g20.utoronto.ca/docs/g20history.pdf, consultado el 10 de marzo de 2015. 


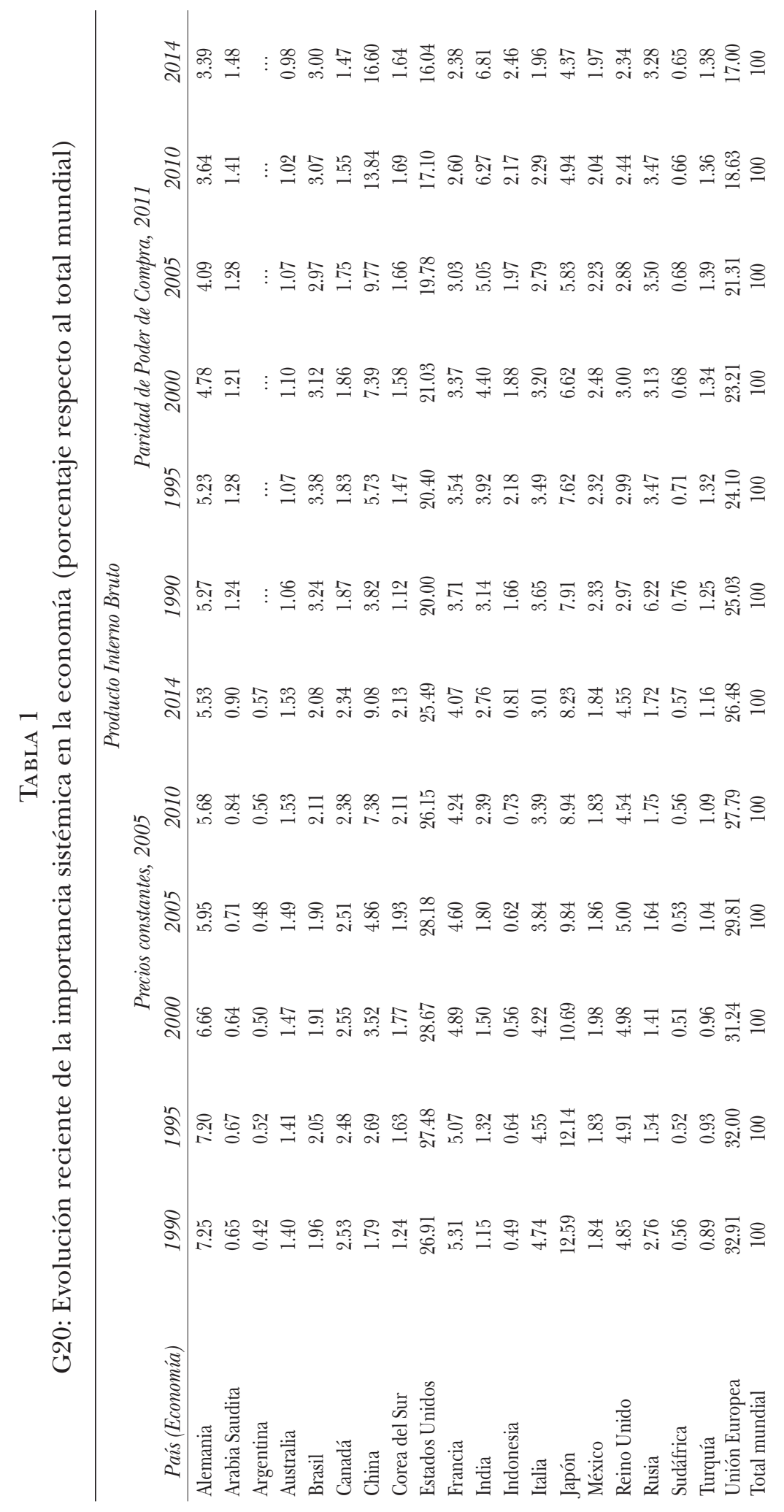




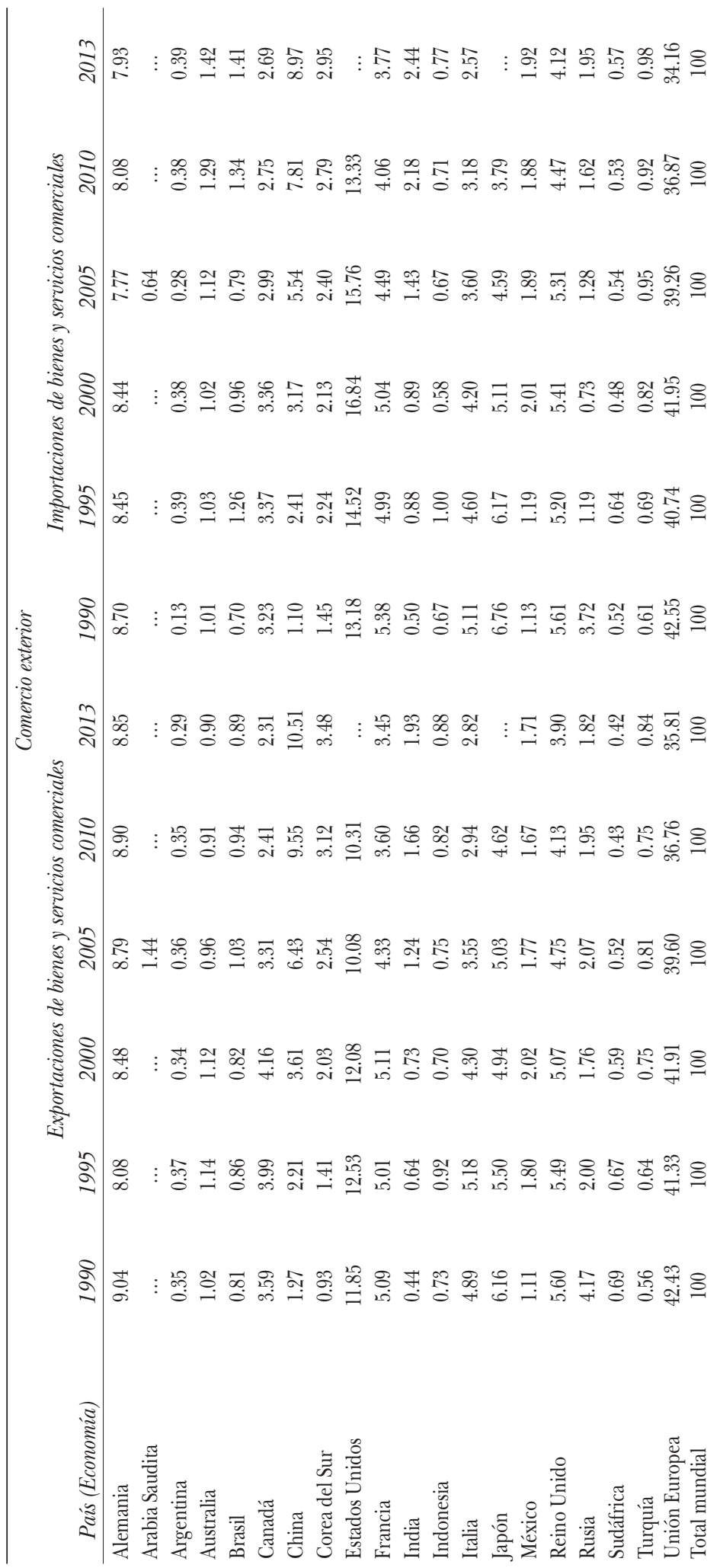


TABLA 1 (concluye)

\begin{tabular}{|c|c|c|c|c|c|c|}
\hline \multicolumn{7}{|c|}{ Inversión extranjera Directa } \\
\hline \multicolumn{7}{|c|}{ Flujos de entrada } \\
\hline País (Economía) & 1990 & 1995 & 2000 & 2005 & 2010 & 2013 \\
\hline Alemania & 1.53 & 3.75 & 15.93 & 3.12 & 2.13 & 1.96 \\
\hline Arabia Saudita & 0.95 & -0.59 & -0.14 & 0.90 & 1.91 & 0.56 \\
\hline Argentina & 0.94 & 1.75 & 0.79 & 0.39 & 0.51 & 0.62 \\
\hline Australia & 4.13 & 3.76 & 1.03 & -1.87 & 2.39 & 2.97 \\
\hline Brasil & 0.50 & 1.52 & 2.48 & 1.15 & 3.49 & 4.86 \\
\hline Canadá & 3.86 & 2.91 & 5.01 & 1.93 & 1.87 & 4.06 \\
\hline China & 1.78 & 11.21 & 2.91 & 8.30 & 17.85 & 20.91 \\
\hline Corea del Sur & 0.40 & 0.56 & 0.70 & 1.02 & 0.62 & 0.73 \\
\hline Estados Unidos & 24.70 & 18.07 & 24.35 & 10.32 & 16.96 & 14.18 \\
\hline Francia & 6.72 & 7.42 & 3.21 & 6.63 & 2.55 & 0.39 \\
\hline India & 0.12 & 0.67 & 0.27 & 0.54 & 1.79 & 1.69 \\
\hline Indonesia & 0.56 & 1.36 & -0.34 & 0.62 & 0.90 & 1.11 \\
\hline Italia & 3.27 & 1.51 & 1.00 & 1.47 & -0.35 & 0.79 \\
\hline Japón & 0.91 & 0.01 & 0.62 & 0.32 & 0.07 & 0.22 \\
\hline México & 1.30 & 2.98 & 1.37 & 1.84 & 1.53 & 2.30 \\
\hline Reino Unido & 17.07 & 6.79 & 9.26 & 18.93 & 4.01 & 2.90 \\
\hline Rusia & $\ldots$ & 0.65 & 0.21 & 0.16 & 2.82 & 4.25 \\
\hline Sudáfrica & -0.04 & 0.39 & 0.07 & 0.49 & 0.24 & 0.49 \\
\hline Turquía & 0.35 & 0.28 & 0.07 & 0.75 & 0.59 & 0.77 \\
\hline Unión Europea & 46.06 & 37.72 & 47.42 & 56.08 & 21.14 & 16.76 \\
\hline Total mundial & 100 & 100 & 100 & 100 & 100 & 100 \\
\hline
\end{tabular}

Fuente: Elaboración propia con datos de Banco Mundial World Development Indicators (actualización al 1.07.2015)

Nota: Las cifras de Rusia para 1990 son aquellas de la URSS. Las cifras históricas de la Unión Europea corresponden al actual número de Estados miembros, suponiendo que hubieran sido miembros en aquél momento.

tradicional "hegemónico" y excluyente. También hizo necesaria la reformulación del concepto del G20 en aras de su efectividad y legitimidad. El Grupo revalorado fue acogido por países no miembros como el nuevo instrumento para lograr una gobernanza económica global. ${ }^{39}$ Ese G20 renovado ahora incluye una formación con reu-

${ }^{39}$ La vertiente de gobernanza global con hace énfasis en los componentes económicos y se centra en proveer bienes públicos globales. Zirahuén Villamar, 
niones cumbre a nivel de jefes de Estado o de Gobierno del G20, así como encuentros más frecuentes a nivel ministerial con una agenda expansiva que dio más cabida a las prioridades de la países emergentes: más allá de la económico-financiera (resultado directo de su pasado desde 1999, incluyendo temas como política fiscal y monetaria, regulación financiera, empleo, comercio y la reforma de las instituciones financieras internacionales), se incluyeron otros temas (que crecientemente se han ocupado de cuestiones energía y cambio climático, o combate a la corrupción). Esta transformación evidencia el nuevo carácter del foro, que ya no puede limitarse a una agenda unipolar, sino que debe corresponder a las prioridades multidimensionales de una membrecía mucho más heterogénea. Hasta finales de 2015 se reunió en nueve ocasiones (véase la tabla 2) y se ha ido conformando una dinámica de interacciones que ha impactado no solamente en el ámbito internacional, sino también en los integrantes del gremio, tanto los desarrollados como los emergentes.

Las cumbres del G20 son eventos mediáticos internacionales que atraen la atención de agentes económicos, políticos y sociales; abren expectativas, orientan conductas de actores públicos y privados y, al menos en los primeros años, han contribuido a la gestión de la crisis económica que hoy se conoce como la Gran Recesión. Pero al mismo tiempo son reuniones que facilitan la convergencia de discursos y visiones que lograron apaciguar el nerviosismo de los mercados y proyectar coincidencias políticas que pudieron disipar las amenazas de una crisis de carácter mundial. El rescate ante la crisis económica global y un paquete de incentivos globales para el crecimiento (2008-2009) han marcado, para algunos observadores, la transición de un comité de crisis a un gremio de regulación global; ${ }^{40}$ dicha transformación ha mostrado ser reversible ante los avances limitados de las cumbres posteriores. El resultado fue un perfil más bajo, medido en atención mediática y de organizaciones políticas

"Transformaciones en la gobernanza económica global: el G20", en Marcela O. López-Vallejo et al., Gobernanza global en un mundo interconectado, México, upAeP/ AMEI, 2013, p. 152.

${ }^{40}$ Andrew F. Cooper, "The G20 as an Improvised Crisis Committee and/or a Contested 'Steering Committee' for the World”, International Affairs, vol. 86, núm. 3, 2010, pp. 741-757. 
nacionales e internacionales, y con menor involucramiento de las organizaciones de la sociedad civil. La columna vertebral del trabajo del G20, las reuniones ministeriales de finanzas y de banqueros centrales, no dejan de ser importantes, pero empiezan a mostrar el desgaste del interés o prioridad que todos los países miembros del Grupo están pasando. Esta percepción puede adelantarse, por ejemplo, al considerar la diversidad cada vez mayor de la agenda, el carácter genérico de las declaraciones y los extensos compromisos que cuestan trabajo materializar. ${ }^{41}$ Retomando los elementos que caracterizan la política exterior de países emergentes, queda evidente su compatibilidad con el nuevo espacio del G20 que respeta plenamente su énfasis en la soberanía nacional y la prevalencia del Estado nacional, corresponde a su preferencia por acuerdos intergubernamentales y abre el espacio para su interés de tener mayor involucramiento en términos de agenda settingy participación. Es en este sentido que la mayor heterogeneidad del G20 está potenciando el espacio de acción de los países emergentes desde sus estrategias de política exterior al privilegiar sus prioridades nacionales y formar "coaliciones ad hoc" ${ }^{42}$ que cruzan las líneas divisorias del pasado entre Norte y Sur, con lo que desarticulan los significantes de la tradicional identidad del Sur Global. No se puede dudar de la importancia que tuvo el same boat spirit en el G20 a la altura de las crisis agudas, que permitió que los mismos países emergentes como Brasil, China y Turquía proporcionaran recursos frescos al FMI y al Banco Mundial para aumentar su capacidad de respuesta en la crisis del euro. ${ }^{43}$

${ }^{41}$ Por ejemplo, las medidas de la estrategia de crecimiento del G20 aprobadas en la cumbre de Brisbane (noviembre de 2014) conocido como el Plan de Acción de Brisbane, que "incluyen cerca de 1000 compromisos individuales de política estructural, de los cuales más de 800 son nuevos” según oEcD/IMF, Quantifying the Impact of G-20 Member's Growth Strategies, 2008 (Report). Asimismo, véase la numeralia citada por John Kirton, aunque ese autor sostiene el argumento contrario. John Kirton, "The G20 System Still Works: Better Then Ever”, Caribbean Journal of International Relations Ẽ Diplomacy, vol. 2, núm. 3, 2014, pp. 50-51 y 57-58.

${ }^{42}$ Stefan A. Schirm, "Global Politics are Domestic Politics: a Societal Approach to Divergence in the G20”, Review of International Studies, vol. 39, núm. 3, 2013, pp. 685-706.

${ }^{43}$ Declaraciones del G20 en las cumbres de Londres (2009) y de Los Cabos (2012). 
TABla 2

G20: cumbres de líderes y presidencias

\begin{tabular}{lll}
\hline \multicolumn{1}{c}{ Año } & \multicolumn{1}{c}{ Presidencia en turno } & \multicolumn{1}{c}{ Cumbre } \\
\hline \multirow{2}{*}{2008} & Convocatoria del presidente de & Washington, D. C., 14-15 de \\
& Estados Unidos, George W. Bush & noviembre \\
2009, primer semestre & Reino Unido & Londres, 2 de abril \\
2009, segundo semestre & Estados Unidos & Pittsburgh, 24-25 de septiembre \\
2010, primer semestre & Canadá & Toronto, 26-27 de junio \\
2010, segundo semestre & Corea & Seúl, 11-12 de noviembre \\
2011 & Francia & Cannes, 3-4 de noviembre \\
2012 & México & Los Cabos, 18-19 de junio \\
2013 & Rusia & San Petersburgo, 5-6 de sep- \\
2014 & Australia & tiembre \\
2015 & Turquía & Brisbane, 15-19 de noviembre \\
2016 & China & Anatolia, 15-16 de noviembre \\
\hline
\end{tabular}

Fuente: Elaboración propia con datos de G20 Research Group G20 Information Centre. Munk School of Global Affairs, University of Toronto (http://www.g20. utoronto.ca).

\section{LA FUNCIONALIDAD DEL FORMATO DEL G20 PARA LOS PAÍSES EMERGENTES}

Sin lugar a dudas, la presencia de los países emergentes en el G20 es una de las principales características del Grupo y probablemente su mayor virtud, sobre todo cuando se compara a las tres décadas de existencia del G7. En esta sección, por medio de un análisis de la funcionalidad del foro, se aborda la primera pregunta planteada con respecto a la representación de los intereses de los países emergentes según rubros específicos en que tiene lugar dicha presencia y la manera en que se practica.

Un primer acercamiento para tratar de responder esta pregunta se basa en el liderazgo que los países emergentes han tenido como presidentes del G20. Desde 2008 hasta 2015 (véase la tabla 2), de las ahora diez cumbres, sólo una tercera parte ha sido dirigida por países emergentes. De igual manera, puede decirse que 
los países emergentes que han presidido el grupo -con excepción de Rusia- son también los que pertenecen a la Organización para la Cooperación y el Desarrollo Económicos (OCDE). Esta adhesión supone visiones compartidas de economía y políticas económicas con los países desarrollados y menos con las posturas de otros países emergentes y del Sur.

Esta observación confirma otro fenómeno que, por evidente, en ocasiones se pasa por alto: las diferencias estructurales entre economías emergentes y las diversas preferencias de políticas económicas para hacer frente a las realidades económicas. Centrando la atención en las materias de naturaleza económica, la heterogeneidad de los países emergentes en el G20 y las características de operación del Grupo harían suponer que nominalmente existe representación de sus intereses al momento de establecer agendas y conducir los trabajos. Sin embargo, podría discutirse que las visiones más heterodoxas de economía que algunos de los miembros emergentes realizan en sus ámbitos nacionales, aún no son expresadas o incluidas como características de la orientación de políticas que se coordinan en el G20. Pareciera no haber consonancia respecto a posturas de políticas nacionales y compromisos grupales asumidos en las declaraciones. Estas tensiones son más notorias en materia de política comercial y en la imposición de barreras al intercambio incluso entre los propios miembros del grupo. En el marco de las negociaciones del G20, la presión por asumir un consenso, en detrimento de una contradicción con las políticas nacionales, ha sido suficientemente fuerte para imponer acuerdos que obligaron a muchos países emergentes a sacrificar su discurso doméstico en aras de verse como parte de una nueva alianza global para mitigar las (posibles) secuelas de una crisis global.

Pero más allá de sus posiciones sustantivas no hay que perder de vista la dimensión simbólica y de reconocimiento. Siguiendo la interpretación de que todos los Estados actúan con la finalidad de maximizar su estatus, ${ }^{44}$ que identifican relativo a sus competidores, es factible considerar este motivo como central para países emergentes,

${ }^{44}$ Oran Young, "International Regimes. Toward a New Theory of Institutions", World Politics, vol. 39, núm. 1, 1986, pp. 118 ss. 
justamente cuando actúan en un ámbito nuevo como es el G20. Siguiendo esta lógica, se observa un "posicionismo defensivo" 45 que domina el comportamiento de los países emergentes en su proyección hacia los otros integrantes del G20, pero naturalmente también con respecto a sus referentes en el Sur Global o las otras instancias de su membrecía, según el modelo de las múltiples pertenencias. Por lo tanto, recalcaremos en lo que sigue el papel diferente que han jugado -más allá de un consenso básico mínimo- las diversas agrupaciones de "emergentes", llámense BRICS, poderes medios o pequeños países ${ }^{46}$ para hacer escuchar sus voces en el marco del G20.

3.1. El reconocimiento del estatus de los países emergentes como actores sistémicos: la adaptación de las cuotas en los organismos financieros internacionales

La reestructuración del capitalismo occidental "desde dentro" 47 ha sido uno de los ejes analíticos dominantes al describir la actuación de los países emergentes en el marco del G20. Tomando como referente los debates de los años setenta sobre el Nuevo Orden Económico Internacional (NOEI), ${ }^{48}$ hoy en día los actores políticos de los países emergentes están planteando un modelo de reforma que apunta hacia un rediseño de las instancias centrales del sistema económico internacional, las instituciones financieras internacionales (IFI). El Fondo Monetario Internacional y el Banco Mundial,

${ }^{45}$ Joseph Grieco, Cooperation among Nations. Europe, America, and Non-tariff Barriers to Trade, Nueva York, Cornell University Press 1990, p. 40: “... all states are defensively positional and compare performance levels out of fear that others may attain a higher ranking in the issue-area in question".

46 Andrew F. Cooper, "The G20 and Contested Global Governance: BRICS, Middle Powers and Small States", Caribbean Journal of International Relations $\mathcal{E} 0$ Diplomacy, vol. 2, núm. 3, 2014, pp. 87-109.

47 Philip S. Golub, "From the New International Economic Order to the G20: How the 'Global South' is Restructuring World Capitalism from Within", Third World Quarterly, vol. 36, núm. 6, 2013, pp. 1000-1015.

${ }^{48}$ Carlos Dodero H., "El nuevo orden económico internacional: la promesa y la realidad”, Comercio Exterior, vol. 29, núm. 11, 1979, pp. 1212- 1220. 
conocidos comúnmente como las Instituciones de Bretton Woods, siguen siendo el eje central de las políticas internacionales en materia económico-financiera, y son vistos como reductos de tiempos de ajuste pasados sin haberse adaptado a los retos de una economía globalizada. Sus arreglos institucionales muy formales, especialmente el sistema de cuotas para las votaciones y las asignaciones de cargos de liderazgo internos, reflejan más la composición de la economía mundial hacia el final de la Segunda Guerra Mundial. Así carecen de una actualización que permitiera conducir la representación de los países del Sur, ni mucho menos representar adecuadamente la realidad económica global en que países emergentes tienen ahora un producto de tamaño considerable. La disposición de los países emergentes de aportar recursos frescos a las Ifi para que éstas pudieran hacer frente a las necesidades crediticias en la crisis europea refleja un cambio de actitud profundo: ya no se pide su disolución, sino que se opta por un cambio desde dentro que se pretende efectuar a partir de una reasignación de cuotas en su propio seno, como se detalla a continuación.

El eje central de la reforma de cuotas consistía en un proceso de acercar paulatinamente la distribución de éstas al peso real de los respectivos países en la economía internacional, meta que se encuentra todavía muy lejos ante la sobre-representación de los países europeos en este órgano. En el marco de la Cumbre del G20 en Seúl se adoptó un acuerdo para reasignar el 6\% de las cuotas a los países emergentes y mover dos de los 24 directorios del FMI en favor de los países emergentes, correspondiendo así al viejo reclamo por mejorar la representación de los países del Sur en las ifi. Esta revisión de las fórmulas que operan para que las economías emergentes ganen más peso en las decisiones del Fondo ${ }^{49}$ iban a favorecer a China, que alcanzaría a convertirse en el país con la tercer cuota más alta entre los miembros del FMI, de la misma forma en que Brasil, la India, China y Rusia se converti-

49 Ariel Buira, "Las tres crisis del FMI y los obstáculos para su reforma", en Jorge Eduardo Navarrete (coord.), Miscelánea global. Tareas internacionales de México, México, Ceirch-unam, 2008, pp. 295-309. 
rían en miembros de la lista de los diez más grandes stockholders del FMI. Hasta el verano de 2015 se mantiene el bloqueo del Senado de los Estados Unidos por ratificar estos acuerdos y abrir el camino hacia una refinanciación del FMI con fondos propios, y en el Comunicado de la cumbre de líderes Brisbane/Australia (15 y 16 de noviembre de 2014) se dicen "profundamente decepcionados con el continuo retraso" ${ }^{50}$ de la ratificación. Hasta la fecha, está operando con préstamos por parte de los países miembros para poder honrar sus compromisos internacionales. Este retraso de cinco años en la implementación está poniendo a prueba la confianza depositada por parte de los países emergentes en la voluntad de reforma de un actor central del sistema financiero establecido, y ha llevado a que el grupo BRICs adelante su propuesta de poner a funcionar el Banco de Desarrollo BRICS ${ }^{51}$ como alternativa ante el desaire sufrido por Estados Unidos y su compromiso asumido en el marco del G20. Así, el grupo BRICs parece asumir una posición de establecer estructuras paralelas ante la inoperatividad del G20 en un eje central de sus reivindicaciones al G20, insistiendo en su estrategia de negociación de carácter distributivo y privilegiando coaliciones defensivas. ${ }^{52}$ La precariedad del criterio de like-mindedness en este tema del futuro estatus de algunos países emergentes refleja claramente la naturaleza divergente del foro del G20 frente a sus antecesores, la cual a su vez no logra romper el nexo entre los miembros de esta agrupación, a pesar de la invocación insistente de equidad y justicia en favor de los menos poderosos en términos de gobernanza global. Esta situación refleja claramente la ventaja del modelo de "gobernanza a través de clubes" por su orientación en ciertos temas y la flexibilidad de las alianzas internas.

50 G20, Leaders' Communiqué Brisbane Summit, 15-16 November 2014, Brisbane, p. 3 .

51 Stephany Griffith-Jones, “A BRICs Development Bank: A Dream Coming True?”, UNCTAD, marzo 2014 (Discussion Papers núm. 215).

52 Eugénia Da Conceição-Heldt, "Machtverschiebungen in internationalen Organisationen? Schwellenländer als Gestaltungs- und Verweigerungsmächte”, Zeitschrift für Politikwissenschaft, vol. 25, núm. 1, 2015, pp. 99-106. 


\subsection{El acceso a información y conocimientos}

Al participar en el G20, los países emergentes no sólo han podido presentar sus intereses particulares y -de manera limitada- como conjunto dentro el Grupo. Otra de las ventajas radica en la interacción constante de grupos de especialistas para compartir información y experiencias (grupos de trabajo y fuerzas de tarea, comisiones, estudios, seminarios, etc.), con que se resuelve el problema de la incertidumbre que caracteriza las situaciones de interdependencia compleja. ${ }^{53}$ Esto juega un importante papel para los países emergentes y más tradicionalmente para las economías en desarrollo, porque la existencia de disparidad en la posesión de conocimientos y expertise en comparación con los países desarrollados es una de las principales denuncias del Sur. Con la aparición en el G20 de los ministros de finanzas se fortaleció el intercambio de información y experiencia entre los ministerios y bancos centrales de las economías involucradas, al igual que de los organismos financierosinternacionales.

Con la primera cumbre de líderes del G20 en 2008 se abrieron nuevos canales de intercambio particularmente valiosos por la participación de otras organizaciones internacionales, universales como la ONU, otras muy representativas como la Organización Internacional del Trabajo (OIT) ${ }^{54}$ o la Organización Mundial de Comercio (OMC) $;^{55}$ y otra más reducida y orientada en materia de políticas económicas, como la oCDE. ${ }^{56}$ La cooperación entre estas instituciones y el G20, así como el enriquecimiento de la colaboración con otros actores no estatales como organizaciones empresa-

53 "The Hallmark of Complex Interdependence is Uncertainty", en Ernest B. Haas, "Why Collaborate? Issue Linkage and International Regimes", World Politics, vol. 32, núm. 3, 1980, p. 377.

${ }^{54}$ Agencia de la onU especializada en materia laboral y sus políticas. Integrada por 185 Estados miembros, con representación de los gobiernos nacionales parte, pero también de organizaciones patronales y sindicales.

55 Organización encargada de facilitar el comercio y vigilar el cumplimiento de sus propios acuerdos en materia comercial. Integrada por 160 Estados miembros, no es una agencia de la onU.

${ }^{56}$ Organización con 34 países miembros de economía de mercado, la mayoría de ellos desarrollados, especializada en el análisis y propuestas en políticas públicas. 
riales (B20), sindicales (L20), de la sociedad civil (Civil20) o grupos de pensamiento (Think20), han permitido ya no sólo a los gobiernos de los países emergentes aumentar sus contactos e intercambios, sino también a otros segmentos que son afectados por los temas de la gobernanza económica global y que tienen algo que decir al respecto. De esta forma, asociaciones de empresarios respaldan las iniciativas de reactivación económica; los sindicatos a su vez apoyan la creación de empleo resultado de dicha reactivación; y la sociedad civil ha subrayado la necesidad de atender los rezagos causados por políticas y prácticas económicas (desigualdad, contaminación del medio ambiente, etc.), muchas de las veces sin diferencia respecto a su origen nacional, sino en sintonía respecto al tipo de organización de que se trate. Queda evidente que esta función informativa es de mayor importancia para los países emergentes más allá de los BRICs, los cuales por su mismo tamaño pueden recurrir a aparatos burocráticos propios para el desarrollo de sus posiciones. Más bien son aquellos países medianos como Corea del Sur, México o Turquía ${ }^{57}$ los que necesitan movilizar su liderazgo con base en ideas desde una ventana de oportunidad específica (como ser anfitrión o miembro de la troika) para poder impactar sobre el conjunto de los miembros del G20.

\subsection{Participación en la definición de normas y estándares}

Uno de los mayores incentivos que ofrece la existencia del G20 a los países emergentes que en él participan es justamente la oportunidad de interactuar en virtual paridad con los países desarrollados en el ejercicio de gobernanza económica global, con que pueden influir con sus visiones, valores e intereses en la formulación de orientaciones y beneficiándose potencialmente de los recursos movilizados que el Grupo encabeza. Por la forma en que se construye la agenda del G20, es decir, las prioridades de la presidencia en turno, los compromisos adquiridos anteriormente -que

57 Corea fue anfitrión de la Cumbre de Seúl en 2010, México de la Cumbre de Los Cabos en 2012 y Turquía lo será en Antalya en el año 2015. 
constituyen procesos-y las contingencias económicas que puedan surgir, aún sería posible la existencia de un margen para que las economías emergentes puedan introducir sus preocupaciones en las discusiones y trabajos, así como sugerir la forma en que se haga frente a los desafíos de la gobernanza global.

Sin embargo, tampoco parece verificarse una impresión duradera de iniciativas de estándares o normas que atiendan exitosamente problemas de los países emergentes -aunque, como se ha mencionado ya, la heterogeneidad de los emergentes es tan compleja que con dificultad podría señalarse que las visiones one size fits all sean lo que conviene a los países que nos ocupan, porque los resultados del G20 suelen ser más bien genéricos a pesar de los exámenes específicos país-por-país, y las alusiones particulares que puedan hacerse en los párrafos de sus comunicados. En las últimas cumbres se ha notado que las brechas entre los países que forman el Grupo parecen ampliarse, ya sea que se trate de diferencias políticas (como las reacciones europeas contra la actitud rusa en el caso de Ucrania) o económicas (como los paquetes de estímulo fiscal estadounidense vis-à-vis la rigidez fiscal europea y sus variantes intracomunitarias) y reflejan una diversidad de posiciones tan ostensible que permite solamente acuerdos en el mínimo denominador común. 58

\subsection{Acordar marcos de acción comunes}

En un ámbito como el G20, que trata de generar "like-mindedness", el funcionamiento de marcos de acción comunes es uno de los instrumentos centrales para generar convergencia y cohesión. Aun cuando los países desarrollados no siempre comparten las mismas ideas, las diferencias que existen en sus posiciones o estados de sus economías, han podido desarrollar cierta robustez en la formación de la agenda del Grupo en cuanto a los temas de gobernanza económica global. Dicha consistencia no es tan fácil encontrarla entre los países emergentes, nuevamente debido a lo disímbolo de sus

${ }^{58}$ Bernhard Rinke y Ulrich Schneckener, op. cit., p. 24. 
rasgos económicos, políticos y sociales. Pareciera claro que, al analizar las economías emergentes, las diferencias entre componentes de sus estructuras económicas las puede conducir más a la divergencia que a la convergencia; por ejemplo, la posición que los tres países latinoamericanos del G20 (Argentina, Brasil, México) tienen respecto al libre comercio son distintas. Y también, en este mismo ejemplo, cuando México presidió el Grupo en 2012, siendo el primer país latinoamericano en hacerlo, no apareció una prioridad que pudiera señalarse para que haya prestado especial atención a una característica económica de la región.

Aun así, y en coincidencia con una de las características de la gobernanza por clubes, en el G20 se han podido concertar acciones de cooperación muy destacadas, sobre todo al principio de la crisis, con operaciones coordinadas tales como el ajuste de tasas de interés de referencia para enviar señales homogéneas a los mercados. Otro ejemplo contundente de acción común fue devolver el FMI al centro del sistema financiero internacional para retomar el lugar principal en tareas de gobernanza global -aunque después no fuera posible concertar como Grupo una candidatura común para el relevo del Director Gerente del Fondo en el año 2011-al dotarle de más tareas y también más recursos para realizarlas. Naturalmente, la coordinación en el marco del G20 también tiene como propósito alentar otros procesos, tales como propiciar el relanzamiento de la ronda de negociaciones de la omc, conocida como la Ronda de Doha, la cual, si bien no ha sido finalizada, parece haber entrado a finales del año 2013 a una nueva fase de aceleración de acuerdos, donde países del G20 tienen posiciones divergentes y hasta confrontadas, como se destacó en páginas previas. Cabe mencionar aquí también que estas diferencias pudieron atestiguarse ese mismo año, cuando dos de los países latinoamericanos del Grupo contendieron entre sí para lograr la Dirección General de la oмc.

De esta forma, resulta evidente que la cooperación en el marco del G20 para la actuación conjunta tiene sus límites, tanto entre países desarrollados y emergentes, como entre los propios emergentes. No obstante, existen otros ejemplos donde las diferencias entre los miembros del grupo se reducen entre sí, pero se acentúan con respecto al resto del mundo, según se señala enseguida. 


\subsection{Las iniciativas para la seguridad alimentaria}

Cuando en el año 2011 Francia presidió el G20, el gobierno francés puso en agenda el tema de la seguridad alimentaria. Esta iniciativa fue acompañada por la expectativa de que este foro iba a hacerse cargo de un tema para sus debates, cuya importancia se da específicamente para los países menos desarrollados, es decir, aquel grupo de naciones que no se encuentra formalmente representado en este gremio. Así, se esperaba un proceso de ampliación de agenda más allá de los intereses inmediatos de los países emergentes hacia el ámbito más general de un problema global cuya incidencia sin embargo afecta a aquellas naciones que sufren los efectos de la volatilidad en los precios de productos alimenticios, ya sea en cuanto a la producción, ya sea con respecto a sus necesidades de consumo. Reducir la especulación con el desarrollo de los precios para productos agrícolas representaba en este sentido uno de los anhelos más articulados, ya que ésta se está realizando en los mercados bursátiles de los países desarrollados y emergentes, que representan también aquella parte del mundo que logra producir excedentes de alimentos que podrían estar sujetos a regulaciones adecuadas para no afectar las economías menos desarrolladas en el mundo. Queda evidente que en materia de seguridad alimentaria cambian de pronto las líneas de conflicto de intereses del patrón establecido entre países desarrollados y emergentes a un nuevo molde: por un lado los países desarrollados y emergentes; por el otro lado, los países menos desarrollados $\left(\operatorname{LDC}^{59}\right)$ con alta vulnerabilidad a los precios de alimentos. Sin embargo, hay que recordar que en los mismos países emergentes sigue existiendo un nivel muy alto de pobreza y desnutrición, por lo cual los gobiernos de estos países deberían estar interesados en promover políticas de carácter estructural para aliviar la situación cambiante en los mercados internacionales de alimentos. $\mathrm{Al}$ mismo tiempo, en muchos integrantes del grupo de "emergen-

${ }^{59}$ La lista actual de los "Least Developed Countries" puede consultarse en la página del Alto Representante de la onu para los Países Menos Desarrollados UN-OHRLLS: http://unohrlls.org/about-ldcs/, consultado el 15 de marzo de 2015. 
tes" se aplican políticas de subsidio para biocombustibles, se recurre al uso indisciplinado de prohibiciones para la exportación y se proporcionan excesivos subsidios agrícolas. ${ }^{60}$

Esta doble identidad de los emergentes en esta materia implicó también que el rendimiento del G20 con respecto a la seguridad alimentaria demostrara tener sus límites. A pesar de que se disponía de una recomendación muy amplia de las medidas a tomar, avalada por organismos internacionales, ${ }^{61}$ no se logró ningún avance en el control de las dinámicas volátiles de los mercados internacionales; más bien se optó por ayudas para la información y transparencia de los mercados y el manejo de riesgos para aquellos países expuestos a sus efectos negativos, llamando a la comunidad internacional a una expansión de la producción de alimentos. Con esta orientación, el G20 prefirió ocuparse de los temas políticamente "más seguros" de productividad, información y ayuda de emergencia, dejando a un lado los temas centrales de carácter estructural en materia de seguridad alimentaria. ${ }^{62}$ No debe sorprender entonces que la actuación del G20 ha sido caracterizada como frustrante, no solamente frente a los retos que plantea el problema, sino también por su bajo rendimiento frente a otras entidades como el Panel de Alto Nivel de Expertos (HLPE) y el Comité para Seguridad Alimentaria Mundial (CFs: UN Commitee on World Food Security). ${ }^{63}$ Algunos autores le reclaman al G20 justamente en este tema haber actuado como self selected oligopoly que corresponde a un multilateralismo de los grandes. ${ }^{64}$ Este juicio alcanza también a la actuación de los países emergentes que decidieron seguir su doble identidad en el tema de la seguridad alimentaria,

${ }^{60}$ Jennifer Clapp y Sophia Murphy, "The G20 and Food Security: A Mismatch in Global Governance”, Global Policy, vol. 4, núm. 2, 2013, p. 130.

${ }^{61} \mathrm{FAO} / \mathrm{IFAD} / \mathrm{IMF}$ /OECD/UnCTAD/WFP/World Bank/WTO/IFPRIUN-HLFT, Price Volatility in Food and Agricultural Markets: Policy Responses, 2011 (Report).

${ }^{62}$ Jennifer Clapp y Sophia Murphy, op. cit., p. 133.

63 Jeroen J.L. Candel, "Food Security Governance: Systematic Literature Review”, Food Security, vol. 6, núm. 4, 2014, pp. 592.

${ }^{64}$ Jakob Vestergaard y Robert Wade, "The G20 has Served its Purpose and Should be Replaced”, Journal of Globalization and Development, vol. 2, núm. 2, 2012, p. 13. 
sacrificando su cercanía con el Sur Global y privilegiando la posición de apoyo al sistema comercial y económico existente. Esta ambigüedad de las potencias emergentes en el marco del G20 ilustra de nuevo su funcionalidad como plataforma para promocionar temas y participaciones específicos. Sin embargo, esta dimensión no completa la imagen; hay que tomar en consideración los esfuerzos de coordinación entre los países emergentes en esta arena así como dentro de otras formaciones, lo que orienta el debate sobre identidad, que es objeto del presente análisis.

\section{La COORDINACión DE POLÍTICAS DE LOS PAÍSES EMERGENTES EN EL MARCO DEL G20}

Para responder a la segunda pregunta, referida a la identidad propia, a patrones de actividad diplomática y superación de dudas sobre responsabilidad, capacidad y compromisos entre los países emergentes en el Grupo, es necesario revisar la coordinación que practican dentro y fuera del G20, pues apuntan hacia la existencia de indefinición identitaria. Si a mediados de la década pasada Brasil, China, la India, México y Sudáfrica declararon su interés de articularse en el O/G5 para construir posiciones colectivas en sus reuniones con el G8, era natural suponer que en el G20 estos cinco países podrían optar por fortalecer el mecanismo de consultas y coordinación, ampliándolo para incluir a los otros países emergentes y con grados de desarrollo similar, como podrían ser Argentina, Indonesia o Turquía. Sin embargo, parece que lo que sucedió al momento del ascenso del G20 de finanzas al G20 de líderes fue un proceso de desagregación en la que la participación de los países emergentes dejó de verse como un proceso en construcción de identidad común, para ser una extensión de algo que ya existía y conocían bastante bien. Adicionalmente, los muy diferentes puntos de arranque de cada una de las economías emergentes del Grupo (por ejemplo, el grado de exposición de sus sistemas financieros, sus posiciones fiscales, su preferencia por una política cambiaria específica o su participación en cadenas globales de valor), así como sus posturas en materia de política económica ilustrada en el 
viejo dilema de economía política (más o menos Estado frente a más o menos mercado) supuso un obstáculo para la coordinación de políticas públicas nacionales. Es decir, países que apostaron por acciones con mayor (instrumentos y montos) intervención gubernamental para reaccionar al choque económico (como China) y aquellos que optaron por medidas más limitadas o se abstuvieron de intervenir en ciertos rubros, confiando en que mecanismos automáticos de mercado bastaran para resolver las dificultades del momento (como México). Así el diagnóstico del comportamiento de los emergentes en el G20 arroja un balance muy desequilibrado, en tanto que las alianzas y coaliciones en el marco de este foro no han seguido una línea de comportamiento común más allá de coincidencias ad hoc. Más bien -y a pesar de las coordinaciones intentadas-, no ha habido posiciones conjuntas, sino discrepancias por liderazgos individuales, lo cual ha impedido un frente común. ${ }^{65}$

Para los países emergentes, su nueva pertenencia al G20 les indujo a una política de privilegiar el pleno desarrollo de su estatus individual, y por tanto se hizo innecesario reforzar una actitud cooperativa con los otros emergentes. Se cumplió al mismo tiempo con sus propias preocupaciones, objetivos y medios nacionales incompatibles con los demás países emergentes del G20 post 2008, por lo cual no han desarrollado una coordinación generalizada de políticas públicas. A esta circunstancia se suma una serie de hechos ligados a la conversión del G20 de finanzas en el G20 de líderes en 1999: no podía preverse plenamente, pero ya se vislumbraba la creciente importancia sistémica que tendrían las economías emergentes en la primera década del siglo xxi, lo cual iba a reforzar su orientación integradora en las lógicas de este grupo, sacrificando de alguna manera su base identitaria de Sur Global.

${ }^{65}$ Leonardo Ramos, Javier Vadell, Ana Saggioro y Márcia Fernandes, “A Governança econômica global e os desafios do G-20 pós-crise financeira: análise das posições de Estados Unidos, China, Alemanha e Brasil”, Revista Brasileira de Política Internacional, vol. 55, núm. 2, 2012, p. 23. Estos mismos autores señalan que el protagonismo de China a veces encuentra eco en otros países como Argentina y Brasil, en materia del régimen cambiario estadounidense, en tanto otros como Corea del Sur permanecen neutrales. 
Una dimensión de las políticas de pertenencia múltiple que caracteriza a los países emergentes es la coordinación que logran establecer con los grupos extra-G20, de los que forman parte. En el G20 hay 19 países, 12 de ellos emergentes, y entre ellos varios grados de desarrollo. Frente a este club de gobernanza, la onU tiene 193 Estados miembros, el вм у el Fмі 188. Esta proporción aproximada de 1 a 10 ilustra la amplitud de opciones posibles para la coordinación entre economías emergentes del G20 por fuera del Grupo, y también con otros emergentes no miembros, lo que parece resaltar la ausencia de "identidad G20" consolidada, como se analiza a continuación siguiendo una dinámica cronológica.

El actor más evidente de los últimos años han sido los BRICs, grupo imaginado por una consultora financiera internacional a principios de siglo como el conjunto de países emergentes que, compartiendo algunas características, podrían determinar el futuro de la economía mundial. ${ }^{66}$ Tuvo que pasar un lustro hasta que los presidentes de Brasil, Rusia, la India y China decidieran reunirse por primera vez en una cumbre en mayo de 2008 -precedida dos años antes por una de cancilleres- para conversar sobre su papel en la economía global y empezar a configurar un club de gobernanza. Con la misma lógica flexible de este tipo de clubes, se organizan alrededor de una presidencia del grupo rotativa cada año entre sus miembros; así y con subsecuentes cumbres anuales, en 2011 Sudáfrica se sumó como miembro de pleno derecho del grupo.

Todos los países del BRICs pertenecen al G20, Rusia incluso perteneció al G8 hasta la primavera de 2014, y a su propio ritmo han ido configurando un foro de discusión de una agenda económica de países emergentes en cuyas respectivas regiones son líderes y varios de ellos tienen proyección global (ya sea por su economía, su población o sus capacidades militares), previendo no sólo la coordinación de políticas sino asimismo una cooperación financiera muy específica: en su cumbre de 2013 en Durban/Sudáfrica, se anunció la creación de un banco de desarrollo

66 Dominic Wilson y Roopa Purushothaman, "Dreaming With BRICs: The Path to 2050”, Goldman Sachs \& Co, 2003 (Global Economics Paper, núm. 99). 
de los países miembros y un acuerdo de reservas contingentes a disposición de los miembros. El alcance en términos de gobernanza global del BRICs es todavía incierto. Dependerá en gran medida de sus propias aspiraciones -en lo individual y en conjunto- y de su capacidad de gestionar las dificultades que generan divergencias entre sus integrantes en materias de política y de seguridad internacionales. Aunque los BRICS se reúnen siempre antes de las Cumbres del G20 para conciliar sus posiciones, hasta la fecha no resulta claro cómo es que lo acordado en el BRICs se refleja en el G20, ya sea en su agenda, sus debates o sus decisiones. Sería arriesgado afirmar la existencia inequívoca de una "identidad BRICs", pero queda evidente que los BRICS están reforzando su actuación externa al G20 para alcanzar mayor visibilidad y peso político en vez de desplegar plenamente su peso en la toma de decisiones internas al G20. Tal comportamiento parecería contribuir a la indefinición de una "identidad G20" de estos países emergentes. Esta tendencia centrífuga de generación y fortalecimiento de identidades más allá del foro del G20 se ha convertido en una nueva dimensión de proyección hacia esta innovación de gobernanza global.

La consolidación del G20 también provocó reacciones articuladas de otros países, que se han considerado como protagonistas de economías emergentes, aunque no fueron considerados sistémicamente importantes para la economía internacional en la conformación del G20. El más notorio es el surgimiento del Global Governance Group (3G), que puede interpretarse como la respuesta de un grupo de países que se sintieron excluidos de las conversaciones del G20 y que decidieron ejercer presión desde fuera sobre los emergentes representados en el G20. A pesar de que el G20 de 2008 aumentó la legitimidad del club de gobernanza en comparación con el G8, la preponderancia mundial que ganó el grupo ampliado alertó a otros países -desarrollados, emergentes y en desarrollo por igual- de la posibilidad de estar ampliando el número de jugadores, pero no las reglas del juego de la gobernanza global, y repetir la práctica de tomar decisiones importantes para la comunidad internacional sin la participación o la consulta de ésta y su principal organización: la onU. En 2010, 
encabezados por Singapur, país emergente emblemático del sureste asiático, varios Estados miembros de la Organización, ${ }^{67}$ todos ellos fuera del G20, ${ }^{68}$ informaron a este grupo su deseo de que las tareas de construcción de gobernanza global contaran con legitimidad, y que para ello tuvieran en cuenta a los países pequeños (sin importar su grado de desarrollo), de modo que pudieran participar consultándoseles. ${ }^{69}$ Con reuniones a nivel ministerial paralelas a las Sesiones de la Asamblea General de la onU, en las cuales examinan los resultados de las cumbres del G20, las declaraciones de dichas ministeriales del $3 \mathrm{G}$ exponen que el diálogo con el G20 es provechoso, e insisten en que la onU debería jugar un papel central en la gobernanza global. Por tanto, invitan al G20 a incluir en sus compromisos la visión de la comunidad en su conjunto, evitar convertirse en un establecedor de estándares que los demás deban seguir y, por el contrario, participar en procesos más amplios en el marco de la onU. Sin combatirlo, el 3G se ha convertido en la conciencia crítica del Grupo de los 20, demostrando que la relación entre economías emergentes y desarrolladas va mucho más allá de los países miembros del G20, y que el multilateralismo debe ser uno de los principales valores de la comunidad internacional. Por lo anterior, el 3G es reticente a ser un club de gobernanza, prefiriendo un G193 (el número de integrantes de la Asamblea General de la ONU), es decir, la primacía del multilateralismo.

Más recientemente, otra agrupación de países surgida de un estudio de una empresa consultora financiera, pero conformada como grupo de coordinación dentro del G20, ha tomado impul-

${ }^{67}$ Bahamas, Bahréin, Barbados, Botsuana, Brunéi Darussalam, Chile, Costa Rica, Emiratos Árabes Unidos, Eslovenia, Filipinas, Finlandia, Guatemala, Jamaica, Kuwait, Liechtenstein, Luxemburgo, Malasia, Mónaco, Montenegro, Nueva Zelanda, Panamá, Perú, Qatar, Ruanda, San Marino, Senegal, Suiza, Uruguay y Vietnam.

68 Aunque Eslovenia y Luxemburgo son Estados miembros de la Unión Europea, que sí es integrante del G20.

69 Iftekhar Ahmed Chowdhury, "The Global Governance Group ('3G') and Singaporean Leadership: Can Small be Significant?”, Institute of South Asian Studies (ISAS), 2010 (Working Paper, núm. 108). 
so en las formaciones de países emergentes. MIKTA es el acrónimo de México, Indonesia, Corea del Sur, Turquía y Australia; todos ellos son integrantes del G20 y, aunque la magnitud de sus economías no es tan grande como la de los BRICs, parecen encaminarse hacia estructuras más estables y sustentables. Identificados como potencias medias y con capacidad de "ser bisagra" entre espacios y actores económicos de dichos espacios, ${ }^{70}$ los ministros de Relaciones Exteriores de estos países se reunieron por primera vez en septiembre de 2013 en Nueva York, nuevamente en abril de 2014 en México y de nuevo en octubre de 2014 en el marco de la Asamblea de la onu. En sus agendas hay temas de política y seguridad internacionales, así como el compromiso de profundizar en sus diálogos asuntos económicos, a fin de que en torno a estas materias puedan coordinarse posiciones en foros internacionales como la onU o el propio G20. ${ }^{71} \mathrm{Al}-$ rededor de este nuevo club de gobernanza hay todavía más expectativas sobre lo que pueden hacer a partir de sus características comunes, y -por ser muy reciente aún- muy pocos hechos para evaluar en términos de su influencia sobre la gobernanza global. Lo que sí se confirma es la proliferación de la gobernanza por clubes, en la cual los países emergentes buscan sus propias vías de coordinación sin renunciar a otros espacios donde participan tanto potencias establecidas como otras emergentes. Con ellas pueden no compartir circunstancias ni aspiraciones, jugando un papel conciliador y no desafiante del statu quo, y que coincide con una visión económica liberal. No debe sorprender entonces que algunos analistas hayan calificado a este grupo incipiente como swing powers ${ }^{72}$, los cuales fungirían como

${ }^{70}$ Günther Maihold, “BRICS, MIST, MIKTA: México entre poderes emergentes, potencias medias y responsabilidad global”, Revista Mexicana de Política Exterior, núm. 100, 2014, pp. 63-79.

${ }^{71}$ Véase el MikTA Vision Statement: http://www.mikta.org/about/vision.php, consultado el 10 de marzo de 2015.

72 MIKTA es un "'block of swing vote shareholders', which depending on the situation may join the groupings of G7, developed countries or BRICS, which oppose each other on many issues, and decide the results of the vote in the framework of G20 in particular". Georgy Toloraya, "MIKTA - Is It a New Element of the Global 
balanza para definir mayorías dentro de este foro. Los miembros de MIKTA, como los de BRICs, realizan prácticas que en aras de las "pertenencias múltiples" podrían aumentar la difusión identitaria y abonar a la poca consolidación de la identidad compartida de país emergente del G20.

La coordinación de políticas entre poderes emergentes ad hoc representa el patrón dominante, ya sea dentro de los espacios bilaterales, los subregionales o los regionales. Sin embargo, la relevancia de estas concertaciones para el proceso del G20 parece ser muy limitado pues los diferentes países se están cuidando mucho de asumir una representación o de ser reconocidos como representantes de una región. Esto puede ejemplificarse para el caso de Brasil, donde el activismo del presidente Lula da Silva en la descripción de su política exterior, donde se niega "cualquier alusión explícita al 'liderazgo brasileño' y en cambio se opta, según palabras del presidente, por tener una 'influencia política sin liderazgo' en América Latina”. ${ }^{73}$ Situaciones parecidas pueden mencionarse para el caso de la República Sudafricana, la India e Indonesia, países inhibidos para asumir abiertamente un liderazgo regional o -como en el último caso- para el mundo islámico. Estas situaciones limitan una posible vocería de los poderes emergentes para otros países e implican un fuerte freno para un posible papel más articulado del Sur Global.

Conclusión. Los PAíses EMERGENTES EN EL G20, ENTre REFORMISMO Y SOCIALIZACIÓN

Si el discurso oficial de que el G20 representa el lugar del desarrollo de "metas compartidas y ventajas mutuas" ${ }^{74}$ con un tránsito de

Governance Structure?", Russian International Affairs Council, 23 de diciembre de 2013 (Multipolar World Analysis).

73 Gladys Lechini y Clarisa Giaccaglia, "El ascenso de Brasil en tiempos de Lula. ¿Líder regional o jugador global?”, Revista Problemas del Desarrollo, vol. 163, núm. 41, 2010, p. 63.

${ }^{74}$ Paul Cammack, "The G20, the Crisis, and the Rise of Global Developmental Liberalism”, Third World Quarterly, vol. 33, núm.1, 2012, p. 12. 
los polos de poder de Occidente al Oriente asiático y al Sur, lo que corresponde a los cambios tectónicos surgidos especialmente con el auge económico de China, entonces el papel de los países emergentes en este marco sería uno de protagonismo de la transición de poder. Se estaría asistiendo al surgimiento de un nuevo patrón de gobernanza económica global. Sin embargo, estas valoraciones se confrontan con juicios que ven al G20 y sus cumbres en un nivel bajo de rendimiento, que observan una caída de la efectividad de este foro, clamando por un esfuerzo de liderazgo sostenido por parte de los Estados miembros para lograr la transformación del G20 en una organización multilateral efectiva. ${ }^{75}$

No obstante, esta exigencia parece no corresponder a los intereses de los países emergentes, en cuya orientación domina un comportamiento de hedging, de control de riesgos por efecto de mantener abiertas al máximo sus opciones. Por lo tanto, la expectativa de que puedan asumir un papel reformista en favor de los intereses del Sur Global ha demostrado ser poco fundamentada, ya que asumen un compromiso limitado debido a su estatus de stake-holder actuando como conservative free-riders ${ }^{76}$ por su aversión a posibles riesgos. Un rasgo muy significativo en esta orientación es su comportamiento en una clara posición soberanista para garantizar un máximo de discrecionalidad nacional en materia económica y política, dando prioridad a las necesidades internas. Un indicador de esta preferencia puede encontrarse en el rechazo práctico del proceso de evaluación mutua (peer review), que el G20 trató de instalar a través del Mutual Assessment Process (MAP), acordado en la Cumbre de Seúl en 2010 y encargado en su implementación al FmI. ${ }^{77}$ Así, en la actualidad se puede detectar más bien una tendencia de moderada reforma en cuanto a la presencia

${ }^{75}$ Gabriel Goodliffe y Stephan Sberro, "The G20 after Los Cabos: Illusions of Global Economic Governance”, The International Spectator, vol. 47, núm. 4, 2012 , pp. 1-16.

${ }^{76}$ Miles Kahler, "Rising Powers and Global Governance: Negotiating Change in a Resilient Status Quo”, International Affairs, vol. 89, núm. 3, 2013, p. 712.

${ }^{77}$ Fondo Monetario Internacional (FMI), "The G-20 Mutual Assessment Process (MAP)", Factsheet, 22 de septiembre de 2014, https://www.imf.org/external/ $\mathrm{np} /$ exr/facts/g20map.htm, consultado el 10 de marzo de 2015. 
de los poderes emergentes en el G20, que se ocupa más de las reglas para llegar a decisiones y en la evolución institucional que de asuntos sustantivos. ${ }^{78}$ En este sentido las potencias emergentes no han podido superar la función de norm-taker, aunque lograron efectivamente avances en los rubros de agenda-setting, el anhelo de fungir como broker (en el caso de MIKTA) y formar alianzas y coaliciones ad hoc.

En síntesis, en este texto se ha hecho énfasis en dos temas de importancia para los países emergentes vinculados al G20: identidad al pertenecer, responsabilidad y compromisos asociados; y funcionalidad del foro para la representación de sus intereses en la mudanza de poder mundial. Para el análisis de ambos elementos, en las secciones precedentes se ha elaborado un análisis que arroja luz a los cuestionamientos planteados en la introducción, aunque difícilmente pueden ofrecer una respuesta definitiva, pues se trata de un debate, en marcha desde las Relaciones Internacionales, de un fenómeno también en sucesión constante, y claramente inacabado: el global shift.

Así, se ha observado que el énfasis del G20 en la igualdad de los participantes los ha llevado a una posición de convergencia hacia el statu quo, privilegiando reformas dentro del sistema. Esta inclinación es reflejo de su preferencia para acuerdos intergubernamentales y distancia a redes híbridas con organizaciones no gubernamentales, que implicarían la necesidad de mayores debates sobre su papel dentro del G20. Que la arena del G20 haya servido como espacio de socialización y adaptación de los países emergentes a las reglas establecidas del sistema internacional existente, es un resultado muy visible en la revisión de algunos temas de la agenda de este gremio. Ello habla de la generación de un esbozo de identidad. No se vislumbran actuaciones y posiciones reformistas entre los integrantes, ni mucho menos actitudes que indiquen estrategias extra-institucionales para intentar minar este foro, como podría ser la ausencia temporal o el abandono por parte de alguno de los miembros. Más bien, se han hecho evidentes los efectos de la interacción entre este grupo de Estados en 
tanto que su repertoire de política exterior se ha ido ajustando a las normas dominantes, no solamente en las estrategias de acción, sino también en la toma de decisiones. ${ }^{79}$ A pesar del incumplimiento de los acuerdos para revisar las cuotas en el FMI por parte de los Estados Unidos, no se han dado efectos disruptivos dentro del G20. En el tema de la seguridad alimentaria, los emergentes asumieron el patrón de comportamiento de los países desarrollados y se quedaron con medidas políticas de aplacar las inquietudes y no optar por una intervención de los mercados internacionales de alimentos. Al parecer la institucionalización de la participación de los países emergentes en el marco del G20 sí tuvo éxito, en tanto que logró centrar sus aspiraciones en esta arena de negociación, aumentando los costos para acciones en contra de este club. La conformación de los países emergentes con el formato del G20 tiene mucho que ver con el proceso de su reconocimiento como actores "sistémicamente importantes" en el proceso de la gestión conjunta de las crisis económicas mundiales, lo cual abrió un camino de inclusión en la toma de decisiones del conjunto de los Estados que se asumieron como los más importantes a nivel mundial, pero sin reclamar para sí el papel de global governor. ${ }^{80} \mathrm{Un}$ hecho que ha facilitado esta percepción de credibilidad y capacidad persuasorias de los consensos es la manera de incluir a los organismos internacionales como el FMI, Banco Mundial, oIT, FAO, OcDE en las deliberaciones de las cumbres, de manera que se pudo entablar por esta vía una sensación de esfuerzo conjunto a nivel muy amplio. Esto habla de la funcionalidad positiva del foro para los países emergentes.

Hasta la fecha no se ha consolidado un discurso entre los miembros que indicaría la percepción de que el G20 estaría actuando con base en fórmulas huecas y declaraciones falsas, lo cual puede interpretarse como un signo de la internalización de sus procedimientos y una caracterización institucional, que sustenta una respuesta afirmativa -aunque insuficiente para hablar de contundencia- en términos de generación de identidad. Las críticas

${ }^{79}$ Kai Alderson, op. cit., p. 417.

${ }^{80}$ Deborah D. Avant, Martha Finnemore y Susan K. Sell (comps.), Who Governs the Globe?, Cambridge, Cambridge University Press, 2010. 
provienen más bien de parte del Sur Global, es decir de aquellos países y voces de la sociedad civil que no se sienten representados en el G20 y reclaman su participación o, más bien, denuncian la falta de legitimidad de este gremio y de sus decisiones. A pesar de sus características informales, el G20 parece permitir una mayor "ownership" en las decisiones por parte de los miembros, ya que se da una base más amplia de inclusión de actores, lo que hace difícil sumarse a posiciones que ponen en entredicho el carácter vinculante de los acuerdos. En este debate se ubica también la pregunta de su futuro desarrollo, es decir, si los países emergentes promueven un G20 en su actual alcance como un comité de crisis o si prefieren un avance hacia una entidad regulatoria para el mundo. ${ }^{81}$ Existen indicios que más bien inducen a una cierta cautela en cuanto a la oportunidad y la capacidad de los países emergentes por expandir el papel del G20; más bien son las diferentes agrupaciones de países emergentes (BRICs, 3G, MIKTA) las que tratan de lanzar diferentes planteamientos propios, en el marco de las Naciones Unidas o como intermediarios sistémicos. Esta dispersión de una identidad propia emergente y de las correspondientes capacidades políticas en "pertenencias múltiples" limitan un proyecto y un accionar en común. Además, con la limitante de tener que organizar respuestas a las recurrentes crisis económicas no se han dado oportunidades que hayan facilitado tanto la identificación con el mecanismo y sus resultados como un proceso más abarcador de la conformación de agendas y una función sostenida en cuanto a la gobernanza global.

$\mathrm{Al}$ final de cuentas, los poderes emergentes miembros del G20 no demuestran un comportamiento diferente a los poderes tradicionales ${ }^{82}$ al seguir el patrón de extraer el máximo de beneficio de su participación en el incipiente nuevo orden internacional, y al tratar de sacrificar lo menos posible su autonomía de decisión. Su norte sigue siendo la lógica de un "posicionismo defensivo", orien-

81 Andrew F. Cooper, "The G20 as an improvised crisis", op. cit., y también Karoline Postel-Vinay, Le G20, laboratoire d'un monde émergent, París, Presses de Sciences Po, 2011, p. 111.

${ }^{82}$ Miles Kahler, op. cit., p. 712. 
tación que de alguna manera es consecuencia de lograr consolidar su posición según una estrategia de pertenencias múltiples, expresión de sus identidades dobles en las diferentes issue-areas. Su actitud cautelosa en asumir posiciones de liderazgo y la aversión al riesgo por posibles costos políticos en la dimensión doméstica, limitan también su papel de iniciativa en favor de los países del Sur Global, por lo cual la arena del G20 no se ha convertido en el lugar de la gran negociación entre Norte y Sur, sino más bien en un comité de crisis para controlar situaciones de emergencia.

\section{BibLIOGRAFÍA}

Acharya, Amitav, The End of American World Order, Cambridge, TJ International Ltd, 2014.

Alderson, Kai, "Making Sense of State Socialization", Review of International Studies, vol. 27, núm. 3, 2001, pp. 415-433.

Avant, Deborah D.; Finnemore, Martha y Susan K. Sell (comps.), Who Governs the Globe?, Cambridge, Cambridge University Press, 2010.

Beeson, Mark y Stephen Bell, "The G20 and International Economic Governance: Hegemony, Collectivism, or Both?”, Global Governance, vol. 15, núm. 1, 2009, pp. 67-86.

Buira, Ariel, "Las tres crisis del Fmi y los obstáculos para su reforma", en Jorge Eduardo Navarrete (coord.), Miscelánea global. Tareas internacionales de México, México, Ceirch-unam, 2008, pp. 295-309.

Busch, Marc L., "Overlapping Institutions, Forum Shopping, and Dispute Settlement in International Trade", International Organization, vol. 61, núm. 4, 2007, pp. 735-761.

Cammack, Paul, "The G20, the Crisis, and the Rise of Global Developmental Liberalism”, Third World Quarterly, vol. 33, núm.1, 2012, pp. 1-16.

Candel, Jeroen J.L., "Food Security Governance: Systematic Literature Review”, Food Security, vol. 6, núm. 4, 2014, pp. 585-601.

Castañeda, Jorge G., "Not Ready for Prime Time. Why Including Emerging Powers at the Helm Would Hurt Global Governance", Foreign Affairs, vol. 89, núm. 5, 2010, pp. 109-115.

Chowdhury, Iftekhar Ahmed, "The Global Governance Group ('3G') and 
Singaporean Leadership: Can Small be Significant?”, Institute of South Asian Studies (ISAs), 2010 (Working Paper núm. 108).

Clapp, Jennifer y Sophia Murphy, "The G20 and Food Security: a Mismatch in Global Governance”, Global Policy, vol. 4, núm. 2, 2013, pp. 129-138. Commission on Global Governance, Our Global Neighborhood. The Report of the Commission on Global Governance, Oxford University Press, 1995 (Report).

Cooper, Andrew F., "The G20 and Contested Global Governance: BRICS, Middle Powers and Small States", Caribbean Journal of International Relations Ẽ Diplomacy, vol. 2, núm. 3, 2014, pp. 87-109.

Cooper, Andrew F. y Daniel Flemes, "Foreign Policy Strategies of Emerging Powers in a Multipolar World: An Introductory Review", Third World Quarterly, vol. 36, núm. 6, 2013, pp. 943-962.

Cooper, Andrew F., "Las potencias emergentes y el nuevo multilateralismo”, Revista Mexicana de Política Exterior, núm. 94, 2012, pp. 139-162.

Cooper, Andrew F., "The G20 as an Improvised Crisis Committee and/or a Contested 'Steering Committee' for the World", International Affairs, vol. 86, núm. 3, 2010, pp. 741-757.

Cooper, Andrew F., "The Heiligendamm Process. Structural Reordering and Diplomatic Agency", en Andrew F. Cooper y Agata Antkiewicz (comps.), Emerging Powers in Global Governance. Lessons from the Heiligendamm Process, Waterloo, CIGI, 2008, pp. 1-18.

Da Conceição-Heldt, Eugénia, "Machtverschiebungen in internationalen Organisationen? Schwellenländer als Gestaltungs- und Verweigerungsmächte”, Zeitschrift für Politikwissenschaft, vol. 25, núm.1, 2015, pp. 99-106.

Dodero H., Carlos, "El nuevo orden económico internacional: la promesa y la realidad", Comercio Exterior, vol. 29, núm. 11, 1979, pp. 1212- 1220. FAO/IFAD/IMF/OECD/UNCTAD/WFP/World Bank/WTO/IFPRIUNHLFT, Price Volatility in Food and Agricultural Markets: Policy Responses, 2011 (Report).

Ferguson, Niall, Civilization: The West and the Rest, Nueva York, Penguin Books, 2011.

Fondo Monetario Internacional (FMI), "The G-20 Mutual Assessment Process (MAP)", 22 de septiembre de 2014 (Factsheet).

Gnath, Katharina, A Group's Architecture in Flux: The G8 and the Heiligendamm Process, Bolonia, European University Institute, 2010. 
Golub, Philip S., "From the New International Economic Order to the G20: How the 'Global South' is Restructuring World Capitalism from Within”, Third World Quarterly, vol. 36, núm. 6, 2013, pp. 1000-1015.

Goodliffe, Gabriel y Stephan Sberro, "The G20 after Los Cabos: Illusions of Global Economic Governance", The International Spectator, vol. 47, núm. 4, 2012, pp. 1-16.

Grieco, Joseph, Cooperation among Nations. Europe, America, and Non-tariff Barriers to Trade, Nueva York, Cornell University Press, 1990.

Griffith-Jones, Stephany, “A brics Development Bank: A Dream Coming True?”, unctad, marzo del 2014 (Discussion Papers, núm. 215).

Haas, Ernest B., "Why Collaborate? Issue Linkage and International Regimes", World Politics, vol. 32, núm. 3, 1980, pp. 357-405.

Heine, Jorge, "Will They Have Table Manners? The G20, Emerging Powers and Global Responsibility", South African Journal of International Affairs, vol. 17, núm. 1, 2010, pp. 1-11.

Kahler, Miles, "Rising Powers and Global Governance: Negotiating Change in a Resilient Status Quo", International Affairs, vol. 89, núm. 3, 2013, pp. 711-729.

Keating, Vincent Charles y Jan Ruzicka, "Trusting Relationships in International Politics: No Need to Hedge», Review of International Studies, vol. 40, núm. 4, 2014, pp. 753-770.

Keukeleire Stephan y Bas Hooijmaaijers, "The BRICs and Other Emerging Power Alliances and Multilateral Organizations in the Asia-Pacific and the Global South: Challenges for the European Union and Its View on Multilateralism", Journal of Common Market Studies, vol. 52, núm. 3, 2014, pp. 582-599.

Kirton, John, "The G20 System Still Works: Better Than Ever", Caribbean Journal of International Relations Eं Diplomacy, vol. 2, núm. 3, septiembre 2014, pp.43-60.

Kirton, John, G20 Governance for a Globalized World, Farnham, Ashgate, 2013.

Kirton, John, "El G20, el G8, el G5 y el papel de las potencias en ascenso", Revista Mexicana de Política Exterior, núm. 94, 2012, pp. 163-200.

Lechini, Gladys y Clarisa Giaccaglia, "El ascenso de Brasil en tiempos de Lula. ¿Líder regional o jugador global?”, Revista Problemas del Desarrollo, vol. 163, núm. 41, 2010, pp. 53-73. 
Levander, Caroline y Walter Mignolo, "The Global South and World Dis/ Order”, The Global South, vol. 5, núm. 1, 2011, pp. 1-11.

Maihold, Günther, "BRICS, MIST, MIKTA: México entre poderes emergentes, potencias medias y responsabilidad global", Revista Mexicana de Política Exterior, núm. 100, 2014, pp. 63-79.

Maihold, Günther, "Del G8 al G20 y más allá: efectividad y legitimidad", Cuadernos de la Cátedra Humboldt: El G20 y El Nuevo Orden Internacional, núm. 1, 2012, México, El Colegio de México, pp. 25-50.

Malan, Pedro S., "Rebalancing the World Economy: The G20's Potential Role”, en Colin I. Bradford y Wonhyuk Lim (comps.), Global Leadership in Transition: Making the G20 More Effective and Responsive, Washington, D. C., Brookings, 2011, pp. 158-161.

Manz, Thomas, "Allianzen und Gruppen im Global Governance System - Multilateralismus zwischen partikularen Interessen und universellen Anforderungen", Internationale Politik und Gesellschaft, núm. 2, 2007, pp. 25-45.

Mittelman, James H., "Global Bricolage: Emerging Market Powers and Polycentric Governance”, Third World Quarterly, vol. 34, núm. 1, 2013, pp. 23-37.

OECD/IMF, Quantifying the Impact of G-20 Members' Growth Strategies, 2008 (Report).

Postel-Vinay, Karoline, Le G20, laboratoire d'un monde émergent, París, Presses de Sciences Po, 2011.

Ramos, Leonardo, Javier Vadell, Ana Saggioro y Márcia Fernandes, “A Governança econômica global e os desafios do G-20 pós-crise financeira: análise das posições de Estados Unidos, China, Alemanha e Brasil”, Revista Brasileira de Política Internacional, vol. 55, núm. 2, 2012, pp. 10-27.

Rinke, Bernhard y Ulrich Schneckener, "Informalisation of World Politics? Global Governance by Clubs", en Development and Peace Foundation/Institute for Development and Peace (comps.), Global Trends 2013. Peace-Development-Environment, Fráncfort, Fischer, 2012, pp. 21-35.

Schirm, Stefan A., "Global Politics are Domestic Politics: a Societal Approach to Divergence in the G20", Review of International Studies, vol. 39, núm. 3, 2013, pp. 685-706.

Schneckener, Ulrich, "The Opportunities and Limits of Global Gover- 
nance by Clubs", German Institute for International and Security Affairs, 2009 (SWP-Comments C 22).

Schweller, Randall, "Emerging Powers in an Age of Disorder", Global Governance, vol. 17, núm. 3, 2011, pp. 285-297.

Shaw, Timothy M., Antkiewicz, Agata y Andrew F. Cooper, "The Logic of the в (R) ICSAM Model for Global Governance”, en Andrew F. Cooper y Agata Antkiewicz (comps.), Emerging Powers in Global Governance. Lessons from the Heiligendamm Process, Waterloo, CIGI, 2008, pp. 19-44.

Stewart, Patrick, "The Unruled World. The Case for Good Enough Global Governance”, Foreign Affairs, vol. 93, núm.1, 2014, pp. 58-63.

Stewart, Patrick, "Irresponsible Stakeholders?: The Difficulty of Integrating Rising Powers", Foreign Affairs, vol. 89, núm. 6, 2010, pp. 44-53.

Toloraya, Georgy, "MIKTA - Is It a New Element of the Global Governance Structure?", Russian International Affairs Council, 23 de diciembre de 2013 (Multipolar World Analysis).

Vestergaard, Jakob y Robert Wade, "The G20 has Served its Purpose and Should be Replaced", Journal of Globalization and Development, vol. 2, núm. 2, 2012, pp. 1-19.

Villamar, Zirahuén, "Transformaciones en la gobernanza económica global: el G20”, en Marcela O. López-Vallejo et al., Gobernanza Global en un mundo interconectado, México, UPAEP-AMEI, 2013, pp. 151-158.

Wendt, Alexander, Social Theory of International Politics, Cambridge, Cambridge University Press, 1999.

Wilson, Dominic y Roopa Purushothaman, "Dreaming With BRIcs: The Path to 2050", Goldman Sachs \& Co, 2003 (Global Economics Paper, núm. 99).

Young, Oran, "International Regimes. Toward a New Theory of Institutions", World Politics, vol. 39, núm. 1, 1986, pp. 104-122. 